This document is confidential and is proprietary to the American Chemical Society and its authors. Do not copy or disclose without written permission. If you have received this item in error, notify the sender and delete all copies.

\title{
Apatite mineralization process from Silicocarnotite bioceramics: Mechanism of crystal growth and maturation
}

\begin{tabular}{|c|c|}
\hline Journal: & Crystal Growth \& Design \\
\hline Manuscript ID & cg-2020-003224 \\
\hline Manuscript Type: & Article \\
\hline $\begin{array}{r}\text { Date Submitted by the } \\
\text { Author: }\end{array}$ & 10-Mar-2020 \\
\hline Complete List of Authors: & $\begin{array}{l}\text { Rincón-López, July Andrea; Centro de Investigación y de Estudios } \\
\text { Avanzados Unidad Querétaro, } \\
\text { Hermann-Muñoz, Jennifer; Centro de Investigación y de Estudios } \\
\text { Avanzados Unidad Querétaro, Materials Science } \\
\text { Cinca-Luis, Núria; Universitat Politècnica de Catalunya, Departament de } \\
\text { Ciència i Enginyeria de Materials } \\
\text { López-Conesa, Lluís; Universitat de Barcelona, Centres Científics i } \\
\text { Tecnològics } \\
\text { Fernández-Benavides, David; Centro de Ingeniería y Desarrollo } \\
\text { Industrial, Ingeniería de superficies y manufactura aditiva } \\
\text { García-Cano, Irene; Universitat de Barcelona } \\
\text { Guilemany-Casadamón, Josep; Universitat de Barcelona, Centro de } \\
\text { Proyección Térmica (CPT), Dpt. Ciència dels Materials i Química Física } \\
\text { Boccaccini, Aldo; Friedrich-Alexander-Universitat Erlangen-Nurnberg, } \\
\text { Department of Materials Science and Engineering } \\
\text { Muñoz-Saldaña, Juan; Centro de Investigación y de Estudios Avanzados } \\
\text { Unidad Querétaro, Materials Science } \\
\text { Alvarado-Orozco, Juan; Centro de Ingeniería y Desarrollo Industrial, } \\
\text { Ingeniería de superficies y manufactura aditiva }\end{array}$ \\
\hline
\end{tabular}

\section{SCHOLARONE Manuscripts}




\title{
Apatite mineralization process from Silicocarnotite bioceramics: Mechanism of crystal growth and maturation
}

\author{
July Andrea Rincón-López a,b, Jennifer Andrea Hermann-Muñoz ${ }^{\text {a,c }}$, Núria Cinca-Luis d,e, \\ Lluís López-Conesa f,g,h, David Andrés Fernández-Benavides ${ }^{\text {b,i, }}$, Irene García-Cano ${ }^{\mathrm{d}}$, Jose \\ Maria Guilemany-Casadamon ${ }^{\text {d }}$, Aldo Roberto Boccaccini ${ }^{\text {c }}$, Juan Muñoz-Saldaña ${ }^{\text {a* }}$ and \\ Juan Manuel Alvarado-Orozco ${ }^{\text {b,i** }}$
}

a Centro de Investigación y de Estudios Avanzados del IPN, Unidad Queretaro, Libramiento Norponiente \#2000, Queretaro, C.P.76230, Mexico

${ }^{\mathrm{b}}$ Consorcio de Manufactura Aditiva, CONMAD, Av. Playa Pie de la Cuesta No.702, Desarrollo San Pablo, Querétaro, C.P.76125, México

'Institute of Biomaterials, University of Erlangen-Nuremberg, Erlangen, Germany

${ }^{\mathrm{d}}$ Centro de Proyección Térmica (CPT), Dpt. Ciència dels Materials i Química Física,Universitat de Barcelona,c/Martíi Franquès 1, E-08028 Barcelona, Spain

${ }^{\mathrm{e}}$ Departament de Ciència i Enginyeria de Materials, Universitat Politècnica de Catalunya (UPC), Campus Diagonal Besòs, Edifici I. Av. Eduard Maristany, 10-14 08019 Barcelona, Spain

${ }^{\mathrm{f} C e n t r e s ~ C i e n t i ́ f i c s ~ i ~ T e c n o l o ̀ g i c s ~ d e ~ l a ~ U n i v e r s i t a t ~ d e ~ B a r c e l o n a ~(C C i T U B), ~ C / L l u i ́ s ~ S o l e ́ ~ i ~ S a b a r i ́ s ~ s / n, ~} 08028$ Barcelona, Spain

gInstitute of Nanoscience and Nanotechnology (IN2UB), University of Barcelona, 08028, Barcelona, Spain

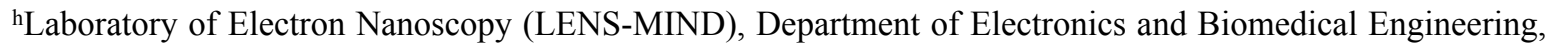
University of Barcelona, C/ Martí i Franquès 1, 08028, Barcelona, Spain

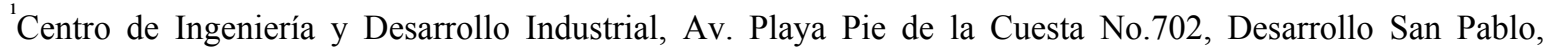
Querétaro, C.P. 76125, Mexico

Corresponding Authors

*(J.M.-S.) E-mail: jmunoz@cinvestav.mx,**(J.M.A.-O.) E-mail: juan.alvarado@cidesi.edu.mx 


\begin{abstract}
A mechanism for the formation and crystallization processes of bone-like apatite grown on non-stoichiometric silicocarnotite (SC) is here proposed. Single-phase SC powders and ceramics were obtained from fixed mixtures of hydroxyapatite and bioactive glass $45 \mathrm{~S} 5$. The bioactive behavior of SC was assessed by immersion in Hank's solution at different times. Afterward, a systematic theoretical-experimental study of the structural properties at the micro and nanoscale using TEM was performed and correlated with SEM, EDX, XRD, and Raman techniques to determine the apatite mineralization process from the SC phase. The initial stage of apatite formation from SC was identified as the hydration and further polymerization of silanol groups, resulting in a silica-based hydrogel, which plays a critical role in the ionic exchange. As a result of the adsorption of ionic species from the medium into the silica-based hydrogel, the precipitation of crystalline apatitic structures starts through the emergence of newly formed SC nanocrystals, which act as a template for the crystallization process of a substituted apatite with SC-like structure. Then, due to the polymorphism between SC and HAp structures, the apatite layer retains the SC periodic arrangement following an epitaxial-like growth mechanism. Identification of the apatite layer formation mechanism is critical to understand its physical and chemical properties, which controls the long-term dissolution/precipitation rate of bioactive materials and their performance in the biological environment.
\end{abstract}

Keywords: Silicocarnotite bioceramic, Apatite mineralization process, Crystal growth, Transmission electron microscopy. 


\section{Introduction}

Third generation biomaterials allow processes of living tissue renewal and regeneration through stimuli at a molecular level and the combination of bioactive and resorbable properties of materials ${ }^{1-3}$. Bioceramics belonging to the $\mathrm{Ca}_{2} \mathrm{SiO}_{4}-\mathrm{Ca}_{3}\left(\mathrm{PO}_{4}\right)_{2}-\mathrm{NaCaPO}_{4}$ ternary system have been recognized to have improved bioactive, biocompatible, osteogenic and angiogenic properties compared to other conventional calcium phosphate ceramics such as hydroxyapatite and $\beta$-tricalcium phosphate, and similar to bioactive glasses ${ }^{4-6}$. These characteristics make this ternary system suitable to develop potential materials to be used in bone tissue engineering applications ${ }^{6-9}$, e.g., fabrication of 3D scaffolds. The biocompatibility and biodegradability of the material combined with a $3 \mathrm{D}$ porous structure result in a biomimetic implant with favorable mechanical properties ${ }^{10,11}$.

One of the phases of this complex ternary system is the $\mathrm{Ca}_{5-\mathrm{x}}\left(\mathrm{PO}_{4}\right)_{2+\mathrm{x}}(\mathrm{SiO} 4)_{1-\mathrm{x}} ; \mathrm{x} \leq 0.3$ phase, also known as silicocarnotite (SC), which crystallizes in an orthorhombic structure, with a $P_{n m a}$ space group and lattice parameters $a=6.737 \AA, b=15.5080 \AA$, and $c=10.132 \AA$ exhibiting a wide range of solid solution with $\mathrm{CaO}, \mathrm{SiO}_{2}$ and $\mathrm{P}_{2} \mathrm{O}_{5}{ }^{12-16}$.

$\mathrm{SC}$ is also considered a highly silicate-substituted $\mathrm{HAp} \mathrm{Ca}_{10}\left(\mathrm{PO}_{4}\right)_{6-\mathrm{x}}\left(\mathrm{SiO}_{4}\right)_{\mathrm{x}}(\mathrm{OH})_{2-\mathrm{x}}$ polymorphism with $\mathrm{x}=2.0$ resulting in the $\mathrm{Ca}_{5}\left(\mathrm{PO}_{4}\right)_{2} \mathrm{SiO}_{4}$ stoichiometry. The lattice parameters $(a, b, c)$ and cell volumes $(V)$ of both crystalline structures have been compared as follows: $a_{\mathrm{SC}} \approx c_{\mathrm{HAp}}, b_{\mathrm{SC}} \approx \sqrt{3} * a_{\mathrm{HAp},}$ and $c_{\mathrm{SC}} \approx a_{\mathrm{HAp}}$ and $V_{\mathrm{SC}} \approx 2 V_{\mathrm{HAp}}{ }^{12}$.

Similarities between SC and HAp structures have enabled the synthesis of SC, starting from a silicon-substituted apatite precursor using mechanochemical or aqueous precipitation methods $12,17-19$. In both cases, the structure of HAp is destabilized due to the formation of hydroxyl vacancies into the hexagonal channel leading to SC formation 12,19 . On the other hand, the sol-gel process or solid-state reaction synthesis routes have also been used to obtain a stoichiometric SC phase ${ }^{20-24}$. Regarding the biological properties of SC ceramics, in-vitro studies have demonstrated the enhancement and acceleration of the osteogenic differentiation process of bone cells in comparison with HAp 20, 25, 26 . 
Despite the promising characteristics of SC, there is a limited number of publications related to the bioactive behavior of this bioceramic and its effect on cell responses. The importance of the material's bioactivity lies in the fact that the formation of a bone-like apatite and the ionic exchange are key characteristics to generate an environment that promotes osteogenesis, resulting in a natural bonding interface between the surrounding tissue and the bioactive material 27,28 . The microstructural characteristics related to the apatite crystal formation, such as size, structure, and morphology affect the biological performance of the material. For instance, needle-like apatite nanocrystals have shown a higher in-vivo osteoinductive potential and degradation compared to large plate-like crystals. Moreover, accelerated osteoinduction and bone healing capacity were observed on smaller and carbonate plate-like apatites $^{28}$.

The mechanism of bone-like apatite formation for Si-containing ceramics in a variety of compositions has been widely reported, including the case of bioactive silicate glasses ${ }^{29-31}$. The presence of Si has been proved to have a significant influence on the nucleation rate and formation kinetics of apatite due to a faster dissolution of silicate ions that later form a hydrated layer formed by a silica hydrogel on the surface, which provides favorable sites for apatite nucleation 31,32. For SC, Serena et al. reported the formation of bone-like apatite on monophasic SC material, finding a layer formed by agglomerates of a silica-phosphate amorphous phase. This layer contains nanometric precipitates of apatite-like phase following the bioactive response of calcium silicate/phosphate biomaterials, and the formation of HAp, $\mathrm{CaO}-\mathrm{SiO}-\mathrm{H}_{2} \mathrm{O}-$ gel $\left(\mathrm{C}-\mathrm{S}-\mathrm{H}\right.$ gel) and $\mathrm{CaO}-\mathrm{SiO}-\mathrm{PO}_{4}-\mathrm{H}_{2} \mathrm{O}-$ gel phase (C-S-P-H gel) based on the $\mathrm{CaO}-\mathrm{SiO}_{2}-\mathrm{P}_{2} \mathrm{O}_{5}-\mathrm{H}_{2} \mathrm{O}$ phase diagram ${ }^{32}$.

Notwithstanding the progress reported so far, an in-depth study, not only of the multilayer apatite formation but also of its crystallization and maturation processes is required to determine the importance of the resemblance of this layer to the mineral phase of bone and the effect of mimicking the chemical and nanostructural features of bone on the cell-material interactions. Regarding the chemical composition of natural bone, it is well known that small contents of ions such as $\mathrm{Na}$ and $\mathrm{Mg}$ may contribute to an accelerated mineralization process 33,34 . 
In the present contribution, a mechanism of formation and maturation of bone-like apatite grown from non-stoichiometric SC ceramics, with $\mathrm{Na}$ and $\mathrm{Mg}$ contents, is proposed based on an integrated analysis of the structural, chemical, and morphological characteristics.

\section{Material and methods}

\subsection{Sample preparation}

Non-stoichiometric SC ceramics were prepared following a processing route reported elsewhere ${ }^{16}$. Briefly, HAp (Cinvestav, Mexico) ${ }^{35}$ and bioactive glass 45S5 (Vitryxx ${ }^{\circledR}$, Germany) powders were ball milled (SPEX 8000D) then pressed using a die with $10 \mathrm{~mm}$ in diameter and sintered at $1220{ }^{\circ} \mathrm{C}$ for $4 \mathrm{~h}$ in a chamber furnace (Thermolyne 46100, Thermofisher Scientific). Phase formation was confirmed by Rietveld refinements of XRD patterns and Raman spectroscopy.

\subsection{Bioactivity and degradation assessment}

Bone-like apatite formation was assessed following the protocols and characterization techniques established in a previous study ${ }^{36}$. Summarizing, SC ceramics were immersed in $25 \mathrm{~mL}$ of a modified Hank's solution (H8264, Sigma-Aldrich, Germany) for periods of 0, 6, 14 , and 28 days at $37^{\circ} \mathrm{C}$ in static conditions, replacing the solution every $3^{\text {rd }}$ day. Samples were characterized before and after immersion using an X-ray diffractometer (XRD), Raman spectroscopy, SEM/EDX, and TEM to identify the structural, chemical, and morphological changes related to apatite formation at the nano and microscale.

SC degradation was evaluated in $\mathrm{pH}$ conditions similar to the physiological environment according to ISO 10993 standard, Part 14: "Identification and quantification of degradation products of ceramic materials" ${ }^{37}$. Ceramics were ground to obtain a homogeneous powder of 325-400 mesh size. Finally, the SC powder was exposed to a buffer solution of TRIS(hydroxymethyl)aminomethane with $\mathrm{HCl}$ with a $\mathrm{pH}$ of 7.4 at $37^{\circ} \mathrm{C} \pm 1{ }^{\circ} \mathrm{C}$ for $120 \pm 1$ $\mathrm{h}$. The quantification of degradation products of $\mathrm{SC}$ was carried out using an inductively coupled plasma optical emission spectrometer (ICP-OES, Optima 8300, Perkin Elmer).

\subsection{Characterization}

\subsubsection{Morphological and chemical changes}

Morphological changes at the surface and cross-section of the samples, before and after 
bioactivity tests were assessed using a scanning electron microscope JSM-7610F (JEOL) with a secondary electron (SE) detector at $1 \mathrm{kV}$ electron acceleration voltage for the surfaces and $10 \mathrm{kV}$ for the backscattering detector (BSE) for the cross-sections characterization. Before SEM measurements, samples were coated with a thin layer of gold-palladium to improve their conductivity. A freshly fracture surface was employed for cross-section evaluation. On the other hand, changes in chemical composition were monitored using an EDX analyzer (Bruker) coupled with the SEM.

\subsubsection{Structure}

Grazing incidence X-ray diffraction (GXRD) at an angle of $1^{\circ}$ was performed to address the structural characteristics of the ceramics before and after exposure to Hank's solution. A Siemens D-500 diffractometer equipment with monochromatic $\mathrm{CuK} \alpha$ radiation $(\lambda=1.5406$ $\AA$ ) operating at $30 \mathrm{kV}$ and $20 \mathrm{~mA}$ was used. The studied region was established in a $2 \theta$ scale using steps of $0.02^{\circ}$ intervals with a counting time of $2 \mathrm{~s}$ at each step. The crystallographic parameters such as phase wt.\%, crystallite size, and lattice parameters of the bone-like apatite and SC phase were obtained by Rietveld refinements of the XRD patterns using GSAS ${ }^{\circledR}$ and following the methodology reported elsewhere ${ }^{35}$.

Local transformations of the SC crystalline phase into apatite were monitored by HRTEM using a JEOL J2010F transmission electron microscope equipped with a field emission electron gun and operated at $200 \mathrm{kV}$. For the HRTEM image simulation, atomic models were created using RHODIUS ${ }^{38}$, and images were simulated using the TEM-SIM software ${ }^{39}$. The procedure reported in ${ }^{36}$ was employed for TEM samples preparation and measurement. In a brief description, SC ceramics were ground in an agate mortar, and the resulting powder was exposed to Hank's solution for 0, 6, and 28 days. The exposed samples were afterward dried in a muffle at $37^{\circ} \mathrm{C}$ for $24 \mathrm{~h}$ and finally dispersed in ethanol and deposited on a $\mathrm{Cu}$ holder. The same procedure reported in ${ }^{36}$ was employed for sample preparation and measurement. Raman spectroscopy measurements were performed before and after bioactivity tests using a confocal Raman microscope (Bruker SENTERRA) with a $532 \mathrm{~nm}$ excitation source, in the $350-3600 \mathrm{~cm}^{-1}$ frequency range, at a spectral resolution of $0.5 \mathrm{~cm}^{-1}$ and an integration time of $40 \mathrm{~s}$.

\section{Results and discussion}


A systematic study was performed at the micro- and nano-scale levels on SC samples before and after Hank's solution immersions to address structural and microstructural changes taking place during the biomineralization process.

\subsection{Morphological and chemical analysis}

Fig. 1 shows micrographs recorded with SEM at different magnifications of the surface of SC ceramics before and after 6 days of immersion in Hank's solution. The surface of assintered SC ceramics is shown in Fig. 1a, where the typical combination of faint microstructure with cracks and pores, is observed ${ }^{16}$. Micrographs with higher magnification are shown in Fig. 1b, evidencing the presence of protuberances and blurred grain boundaries. Homogeneous chemical composition was confirmed, measuring point-by-point using EDX in several areas of the ceramic surface. The correspondent values are reported in Table 1. After 6 days of immersion (Fig. 1c), a considerable increase in superficial cracks and a decrease in surface porosity from $5.32 \pm 0.29$ to $1.27 \pm 0.10 \%$ measured by images analysis using the Image J® software were detected. Moreover, the appearance of nodular structures with diameters around $750 \mathrm{~nm}$ is also noticed, which are randomly distributed all over the surface.

In contrast, nodular structures of about $80 \mathrm{~nm}$ were observed during the apatite mineralization process for stoichiometric SC ceramics ${ }^{32}$, and are considerably lower than the diameter of the structures found in the present work. This effect can be associated with the nonstoichiometry of the SC phase used in this study and the ability to exchange other ionic species. These nodular structures represent the early stages of bone-like apatite formation or immature apatite, which is composed of either amorphous calcium phosphates or calcium silicates and can be considered the basic units of the apatite ${ }^{27,32,35,40}$. The inset of Fig. 1d shows the texture of these nodules and their coalescence to form dune-like apatite aggregates. The composition of the apatite nodules that have grown from the hydrated layer is homogeneous along the surface, covering the entire surface and filling the native porosity of the ceramic. EDX measured higher $\mathrm{Mg}$ and $\mathrm{P}$ contents, and a generalized decrease in $\mathrm{Si}, \mathrm{Na}$, and $\mathrm{Ca}$ contents in comparison to initial ceramic was also observed in Table 1. The coalescence and growth process of dune-like apatite aggregates continues with the immersion time, as it is observed after 14 days of exposure to Hank's solution (Fig. 2a.). 
At this time point, the dune-like apatite agglomerates reached sizes around $3 \mu \mathrm{m}(\sim 4$ times bigger than the size measured at 6 days). The micrograph of Fig. $2 \mathrm{~b}$ shows changes in the morphology of these agglomerates and their microstructure in comparison with the sample immersed by 6 days (Fig. 1d) at the same magnifications. At this stage, agglomerates are formed with thousands of plate-like crystals (Fig. 2d). Moreover, a cross-section of SC ceramics is shown in Fig. 2c, where a dense bone-like apatite layer of about $1.7 \mu \mathrm{m}$ in thickness has grown. The growth behavior, surface roughness, and size values of these dunelike apatite aggregates match with those reported in previous studies ${ }^{41-43}$. In the case of polydopamine-coated tricalcium silicate (TCS) disks after 14 days of immersion in simulated body fluid (SBF) solution, it was suggested the formation of a bone-like apatite layer on the hydrated TCS followed by a layer-by-layer growing mechanism ${ }^{41-43}$.

After 28 days of immersion, a similar microstructure to the one observed at 14 days is noticed (Fig. 3a) with slight differences in the size of the dune-like apatite agglomerates (diameters close to $4 \mu \mathrm{m}$ ) leading to vanished boundaries between them (Fig. 3b). The densification and thickness of the bone-like apatite scale grown on the SC surface are shown in cross-section in Fig. 3c and 3d, where the dense scale is presumably formed by stacking layers of about 3 $\mu \mathrm{m}$ dune-like agglomerates. Additionally, in Fig. 3d the cross-section of a hollow dune suggests the coalescence of agglomerates followed by their densification.

On the other hand, the cross-section image of Fig. 4a shows not only the apatite layer at the surface but also filling the internal pores of SC ceramics due to the penetration of the fluid through the native open porosity of sample, which allows ion-exchange and interdiffusion phenomena after 6 days of immersion. A closer look into the internal pores shows an immature apatite characterized by the presence of elongated nanocrystals with a lens-like morphology distributed within the pores. These morphological features have been previously reported and attributed to the $\mathrm{Mg}$ content into the crystalline phase ${ }^{44,45}$. After 28 days of immersion, a densified apatite is detected inside the pores showing morphological characteristics similar to the apatite observed at the surface (see Fig. 4b). These micrographs confirmed that the formation of apatite in the internal ceramic pores is due to interdiffusion phenomena observable in depths of at least $25 \mu \mathrm{m}$ in the ceramic. This interdiffusion 
mechanism that leads to apatite formation into the ceramics pores agrees with that reported for SC ceramics ${ }^{32}$.

SEM micrographs and EDX measurements suggest a mechanism of apatite formation similar to the reported for other calcium silicates and calcium silicophosphates, in which the precipitation of immature dune-like apatite is developed after the dissolution and hydration of silicon-rich species promoting the nucleation sites for the dissolved $\mathrm{Ca}^{2+}, \mathrm{PO}_{4}{ }^{3-}$ and other ions ${ }^{31,41}$. Once smooth apatite nodules are formed after 6 days, mature apatite results in rounded structures made out of thousands of nanocrystals, as observed in Fig. 1d and 2d. This behavior is a continuous process involving the growth and coalescence of agglomerates resulting in the apatite thickness layer increase reaching around $3 \mu \mathrm{m}$ after 28 days (see Fig. $3 \mathrm{a}$ and $\mathrm{c})$.

The morphological changes observed at the ceramics surface and cross-sections can be correlated with variations in chemical composition, as reported by Zhang et al. in ${ }^{46}$ for CaO$\mathrm{MgO}-\mathrm{SiO}_{2}$-based ceramics. For these cases, the dissolution of $\mathrm{Ca}^{2+}, \mathrm{Mg}^{2+}$, and $\mathrm{Si}^{4+}$ ions were followed by the adsorption of inorganic compounds $\left(\mathrm{Ca}^{2+}, \mathrm{Mg}^{2+}, \mathrm{SiO}_{3}{ }^{2-}, \mathrm{CO}_{3}{ }^{2-}\right)$ through the silica hydrogel layer and the $\mathrm{Mg}$ present in the ceramics reduced the local concentration of $\mathrm{Na}^{+}, \mathrm{Ca}^{2+}$, and $\mathrm{Si}^{4+}$ ions, well as the degradation rate. In the $\mathrm{SC}$ case, a similar phenomenon was observed after 6 and 28 days of immersion, where a continuous increase in the content of $\mathrm{Mg}$ and $\mathrm{Cl}$ and a simultaneous decrease of $\mathrm{Na}, \mathrm{Ca}$, and $\mathrm{Si}$ were detected. The resulting bone-like apatite has a $\mathrm{Ca}+\mathrm{Na}+\mathrm{Mg} / \mathrm{P}+\mathrm{Si}$ ratio of 1.69 , as a result of the maturation and crystallization process. The gradients of the elemental composition of the apatite layer values are reported in Table 1.

\subsection{Structural characterization}

\section{X-Ray Diffraction}

The X-ray diffraction patterns (Fig. 5a) were analyzed by Rietveld refinement using GSAS® to determine structural parameters and, therefore, to track the structural changes that led to apatite formation (Fig. 5b). The refinements were performed using two theoretical patterns: SC PDF 40-393 with Pnma space group and lattice parameters $a=6.737 \AA, b=15.5080 \AA$, $c=10.132 \AA$ to determine the structural changes as a function of the immersion time and 
HAp PDF 9-432 with P63/m space group and lattice parameters $a=b=9.432 \AA, c=6.881$ $\AA$, to quantify the apatite formation.

Structural changes were investigated at different periods of immersion in Hank's solution between 0 to 28 days. After the immersion, a continuous loss in the intensity of SC peaks was noticed (Fig. 5a). The main effects were visible on the peaks in the region between $32.5^{\circ}$ and $35^{\circ}$, with the almost total disappearance of the (133) plane after 28 days of immersion. Moreover, the formation of a new peak around $26^{\circ}$ is observed after 14 days, which corresponds to the (002) plane of the HAp, indicating the presence of a new apatite phase formed from the SC phase. After 28 days, a slight broadening of the main peak of the SC phase in the range of 31.62 to 31.68 , corresponding to the (033) plane, suggests the presence of a second peak identified as the (211) plane of the HAp. The analysis by Rietveld refinement confirmed increments in the apatite content from 30, 55, and 65 wt.\% after 6, 14, and 28 immersion days, respectively (Fig. 4b). Moreover, apatite crystallite size started with values below $100 \mathrm{~nm}$ at 6 days, tripling its size, after 28 days of immersion.

The most important feature to notice at this point for the apatite mineralization process from the SC phase is the absence of the amorphization stage observed in other silicon calcium phosphates and bioactive glasses ${ }^{9,47-49}$. Instead, the shape of the peaks indicates the presence of highly crystalline phases even after 28 days of immersion for the SC ceramics; considering that the apatite thickness is around $3 \mu \mathrm{m}$, the fact that the diffraction peaks of SC phase correspond to the ceramic substrate can be neglected (Fig. 3c).

Although this effect can be observed in different literature reports, no clear explanation has been delivered so far. Therefore, complementary studies based on TEM and Raman spectroscopy measurements and analyses were undertaken in this work.

\section{Transmission electron microscopy}

SC powder was studied before and after immersion in Hank's solution by HRTEM and SAED in the TEM to determine the influence of the original SC crystalline structure on the bone-like apatite formation and its crystallization process at the nanometric scale.

SC particles before immersion are presented in Fig. 6 and Fig. 7. Fig. 6a shows a particle with rounded edges and a size larger than $200 \mathrm{~nm}$. The same area was analyzed by SAED 
(Fig. 6b), and the pattern was indexed according to the [101] zone axis of the SC structure (space group \#62 Pnma, PDF 40-393), evidencing the existence of a single crystalline phase. Fig. 7a and $\mathrm{b}$ revealed a highly periodic arrangement of atoms; in both cases, lattice fringes correspond to a $d=0.28 \mathrm{~nm}$ lattice spacing.

After 6 days of immersion, SC particles interacted with Hank's solution generating two different zones (Fig. 8). A first region is composed of an amorphous layer at the edges or outer sides of the SC particles, which corresponds to the hydrated silica layer, C-S-P-H gel, that allows the ionic exchange between the ceramics and the physiological medium.

The amorphous nature of the zone marked by arrows in Fig. 8a was determined by the absence of electron-diffraction patterns and is evidence of the early stage of the apatite formation. A second region is distinguished in the center of Fig. 8a by the presence of a crystalline zone with a periodic arrangement in which the lattice fringes are highly defined and can be understood either as a stacked array of same-oriented crystals or by a single crystal (Fig. 8b). This zone is the result of the crystallization process of C-S-P-H gel, the ionic species adsorbed and its size matches with the crystallite size determined by Rietveld refinement after 6 days of immersion for both the SC and the apatite phases, which is around $80 \mathrm{~nm}$ (see Fig. $5 \mathrm{~b}$ and c). FFT analysis of Fig. 8b shown in Fig. 8c shows the spots corresponding to the crystalline zone. This result is in contrast to the TEM observations in other calcium phosphates or calcium silicophosphates ${ }^{36}$ after 6 days of immersion, where several crystals are randomly distributed in the amorphous matrix or hydrated layer. It has been reported that this geometry of the growing crystals increases their length with $\mathrm{CO}_{3}{ }^{2-}$ ion contents ${ }^{50}$.

For powders after 28 days of immersion (see Fig. 9 and Fig. 10), crystals with lengths between 200 and $1000 \mathrm{~nm}$ were observed with a different morphology from that before immersion. The edge of the larger crystals is composed of elongated and thin nanocrystals (Fig. 9b) that overlap and form thicker crystals (Fig. 9c), as showed in the darkest areas, which have less pointed edges. These crystals are overlapped in a highly periodic arrangement of a crystalline lattice evidenced in Fig. 10. The pattern contrasts generated by the periodic arrangement in the HRTEM images (Fig. 10a and b) changed in comparison with the SC powder before immersion (see Fig. 6). It is important to remark that the SAED pattern 
in Fig. 10c can be successfully indexed using either the SC structure (space group \#62, Pnma) oriented along the [101] zone axis or the apatite structure (space group \#176, P63/m) oriented along the [120] zone axis.

The lattice fringes associated with a $d=0.527 \mathrm{~nm}$ determined in the inset of Fig. 10a are similar to the theoretical values of $d_{\mathrm{SC}(101)}=0.561 \mathrm{~nm}$ and $d_{\mathrm{HAp} \mathrm{(101)}}=0.526 \mathrm{~nm}$. In the case of the lattice fringes associated with a $d=0.847 \mathrm{~nm}$ are similar to the theoretical values of $d_{\mathrm{SC}(011)}=0.848 \mathrm{~nm}$ and $d_{\mathrm{HAp} \mathrm{(100)}}=0.815 \mathrm{~nm}$. Despite the clear formation of apatite on the surface of SC, the typical interplanar distances of apatite grown from other corresponding calcium phosphates or silicophosphates $d=0.34 \mathrm{~nm}$ and which are associated with the orientation of plane (002) are not observed, being this effect usually observed in natural mineralization processes ${ }^{36,51}$.

Because of the importance of a more thorough understanding of better the nature of this phenomenon, and clarify the presence of SC, apatite, or the coexistence of both, HRTEM image simulations using a multislice approach were conducted using the TEM-SIM software ${ }^{39}$, based on atomic models created using the RHODIUS ${ }^{38}$ software. The atomic models were built up at different growth thicknesses from $0,1,2,4,6$ and $8 \mathrm{~nm}$ of an apatite layer (to imitate different growth times) on a constant $2 \mathrm{~nm}$ SC layer, aligned along the coherent zone axes found in the experimental images (see Fig. 10a). The interaction with the simulated electron beam was carried out perpendicular to the assembly of both layers simulating images of HRTEM taken experimentally at the apatite side. After comparing the HRTEM simulated images with the experimental ones, it can be seen that the simulated image corresponding to the initial SC layer presents a hexagonal contrast pattern, which is in good agreement with the experimental image of the powder before immersion (see Fig. 11b and $h$ ). As the thickness of the apatite layer in the model increases, the hexagonal contrast transforms into horizontal stripes in a preferential direction in the simulation (see Fig. 11d-g). This result is consistent with the stripe contrast observed in the experimental HRTEM image obtained from the powder after 28 days of immersion (Fig. 11i). Based on these results, the possibility of indexing the electron pattern obtained for the SC powders after 28 days of immersion in Hank's solution is associated with the apatite formation mechanism, which mimics the original SC structure. 


\section{Raman spectroscopy}

Raman spectra of SC ceramics recorded before and after immersion in Hank's solution during 6,14 , and 28 days, in the range of $350-3600 \mathrm{~cm}^{-1}$, are presented in Fig. 12. The spectrum of HAp has been incorporated for comparative purposes, in which the main vibrational modes of the HAp phase were identified; the $\mathrm{PO}_{3}{ }^{4-}$ group at a wavenumber around $440 \mathrm{~cm}^{-1}(\mathrm{v} 2$ symmetric bending mode), $600 \mathrm{~cm}^{-1}$ ( $\mathrm{v} 4$ antisymmetric bending mode), $967 \mathrm{~cm}^{-1}$ ( $v 1$ symmetric stretching mode) and $1070 \mathrm{~cm}^{-1}$ (v3 antisymmetric stretching mode) ${ }^{13,16,32}$. For the SC phase before the immersion, the most intense band around the $953 \mathrm{~cm}^{-1}$ showed the combined contribution of phosphate and silicate: the symmetric stretching mode of silicate and the $v 1$ mode of the phosphate group. Representative silicate bands are observed in the range of $848-850$ and $587 \mathrm{~cm}^{-1}$ associated with the $v 1$ and $v 2$ vibrational modes of the $\mathrm{SiO}_{4}{ }^{4-}$ 13,32 .

As the immersion time increases, the intensities of all the vibration modes of the $\mathrm{SiO}_{4}{ }^{4-}$ group are clearly attenuated. Moreover, the characteristic band of the $\mathrm{CO}_{3}{ }^{2-}$ group is visible at about $1090 \mathrm{~cm}^{-1}$ after 6 days of immersion, which has been associated with carboapatite phases ${ }^{13,32}$. On the other hand, vibrations of $-\mathrm{PO}_{3}$ and $-\mathrm{PO}_{2}$ groups in phosphate amorphous phases can contribute to this band broadening between 1000 and $1300 \mathrm{~cm}^{-1}$. Finally, other broadband is observed around $1450 \mathrm{~cm}^{-1}$, which can be related to the presence of $\mathrm{CO}_{3}{ }^{2-}$ groups and Sicontaining apatite phases. Some authors have assigned this band around $1490 \mathrm{~cm}^{-1}$ to a carbonate ion in a carbonated hydroxyapatite phase ${ }^{28,52-54}$. It is important to note that despite the low intensity of the band at $855 \mathrm{~cm}^{-1}$, which is characteristic of SC, the characteristic position of the $\mathrm{SiO}_{4}{ }^{4-}$ mode is kept. It is also worth to remark that the $\mathrm{OH}^{-}$vibration mode at $3574 \mathrm{~cm}^{-1}$, typical of HAp is not observed at any immersion time, and the main peak of the Raman spectra for all samples after immersion showed the same position as the SC sample before immersion. The remaining band at $848 \mathrm{~cm}^{-1}$ associated with the $\mathrm{SiO}_{4}{ }^{4-}$ group suggests that in the formed apatite the $\mathrm{SiO}_{4}{ }^{4-}$ substitute the $\mathrm{OH}^{-}$, which explains the absence of hydroxyl group. This substitution in the apatite structure has already been reported elsewhere $12,17,19$. 
Finally, comparing the spectra of the HAp with the SC samples immersed in Hank's solution, it can be seen that the spectra coincide more with the vibration modes of the SC than those from HAp, including the apatite from SC after 28 days in Hank's solution.

\subsection{Mechanisms of apatite formation and first stages of maturation from SC}

During immersion, specific morphological changes are noticeable at the SC ceramic surface as a result of the interaction with the physiological medium promoting a Si-rich hydrated layer, which provides favorable sites for the nucleation of an apatitic structure ${ }^{32}$. This silica hydrogel formed due to the polymerization of diverse silanol groups (i.e., -Si-O-H) results from the dissolution of silicate ions and its bonding with $\mathrm{OH}$ - groups (see Fig. 7).

An apatite growth formation mechanism from SC has been established by Serena et al. ${ }^{32}$, considering the hydration process of the $\mathrm{CaO}-\mathrm{SiO}_{2}-\mathrm{P}_{2} \mathrm{O}_{5}$ system in which the presence of $\mathrm{H}_{2} \mathrm{O}$ results in the destabilization of SC leading to the formation of an apatite-like structure, calcium silicate and portlandite in $\mathrm{Ca}_{2} \mathrm{SiO}_{4}$-rich $\mathrm{SC}$, while in $\mathrm{Ca}_{3}\left(\mathrm{PO}_{4}\right)_{2}$-rich $\mathrm{SC}$, the hydration results in the formation of $\mathrm{HAp}, \mathrm{CaO}-\mathrm{SiO}-\mathrm{H}_{2} \mathrm{O}-$ gel $(\mathrm{C}-\mathrm{S}-\mathrm{H}$ gel $)$ and $\mathrm{CaO}-\mathrm{SiO}-$ $\mathrm{PO}_{4}-\mathrm{H}_{2} \mathrm{O}-$ gel phase (C-S-P-H gel). Moreover, the SC obtained in this work from the $\mathrm{HAp} / \mathrm{BG}$ mixture is a $\mathrm{Ca}_{3}\left(\mathrm{PO}_{4}\right)_{2}$-rich, as was previously reported in ${ }^{16}$. Based on this, after immersion in Hank's solution, the formation of apatite-like structures, C-S-H, and C-S-P-H hydrogels, due to SC hydration, will be expected. The processes of precipitation and crystallization in different apatite structures are the result of a dynamic ionic exchange between the exposed material and ionic species available in the physiological medium.

Rietveld refinement results in Fig. $5 b$ indicates the formation of a bone-like apatite as expected from the hydration process. At the same time, the presence of the SC phase is also evidenced. Since the bone-like apatite layer observed after 14 days of immersion (see Fig. 2c) presents a homogeneous thickness along the entire surface of about $2 \mu \mathrm{m}$, there is no possibility that the XRD SC peaks observed in Fig. 5a originate from the SC original surface. These experimental observations lead us to raise the following hypothesis: The SC phase observed after the immersion process is a result of the adsorption of ionic species from the medium into the C-S-P-H gel, giving the conditions for the SC precipitation process. Being these new SC crystals, the structural template that conduces to the growth of a bone-like 
apatite with similar SC crystallographic characteristics. This mechanism is presented in Fig. 13.

Based on this, the following reasoning is proposed to describe the bone-like apatite growth from SC. It is known that the C-S-H and C-S-P-H gels act as precipitation media for the crystalline formation of apatitic structures such as HAp and SC, considering that a highly silicate-substituted HAp $\mathrm{Ca}_{10}\left(\mathrm{PO}_{4}\right)_{6-\mathrm{x}}\left(\mathrm{SiO}_{4}\right)_{\mathrm{x}}(\mathrm{OH})_{2-\mathrm{x}}$ with $\mathrm{x}=2.0$ results in an $\mathrm{SC}$ $\mathrm{Ca}_{5}\left(\mathrm{PO}_{4}\right)_{2} \mathrm{SiO}_{4}$ stoichiometry ${ }^{12,13}$.

Comparing both crystallographic structures, it can be observed that they share the same $\mathrm{FW}_{\mathrm{SC}}=\mathrm{FW}_{\mathrm{HAp}}\left(1\right.$ formula weight, $\left.265 \AA^{3}\right)$ and have a $\rho_{\mathrm{SC}} \approx \rho_{\mathrm{HAp}}{ }^{12,13}$. Additionally, the relationships between their lattice parameters are $a_{\mathrm{SC}} \approx c_{\mathrm{HAp}}, b_{\mathrm{SC}} \approx \sqrt{ } 3 * a_{\mathrm{HAp}}$, and $c_{\mathrm{SC}} \approx a_{\mathrm{HAp}}$ and $\mathrm{V}_{\mathrm{SC}} \approx 2 \mathrm{~V}_{\mathrm{HAp}}$. These similarities between both structures give the conditions for epitaxial growth. The HRTEM image simulations support this affirmation in Fig. 11; the simulated structures assembly at different HAp thickness model the experimental mineralization process, which results in the epitaxial bone-like apatite growth, mimicking the SC structure. This growth behavior allows indexing the SAED pattern in both crystalline structures. With these bases, we propose that the crystallization process of C-S-P-H gel into SC acts as a preconditioning matrix to guide the crystallization of highly silicate-substituted HAp. This statement might explain the lack of changes in the XRD patterns after immersion (see Fig. 5) and the remnant vibrational mode of $\mathrm{SiO}_{4}{ }^{4-}$ in the Raman spectrum and the absence of the $\mathrm{OH}^{-}$group (see Fig. 12).

The closeness and similarity between both structures promote the growth of a bone-like apatite structure aligned to the main crystallographic planes of SC minimizing the nucleation barrier and accelerating its crystallization process as observed after 6 days of immersion (Fig 5 ) in comparison with the crystallization process of other calcium phosphates in HAp ${ }^{36}$. Both phases exhibit very close main diffraction peaks, as can be observed in Fig. 5a; the main peak of SC is located in the range of 31.62 and $31.68^{\circ}(2 \theta)$ with interplanar distances between 0.283 and $0.282 \mathrm{~nm}$, while one of the HAp main peaks is at $31.78^{\circ}$ with an interplanar distance of $0.281 \mathrm{~nm}$.

Additionally, results of crystallite size and lattice strain associated with the $a$ parameter of 
SC remaining phase after 6, 14, and 28 immersion days are presented in Fig. 5c. Before and after ceramic's immersion, SC crystalline phase was identified with strains in its lattice parameters calculated using equation 1 . The SC phase quantified by Rietveld refinement as a function of the immersion time shows an abrupt decrease of the $a$ lattice parameter after 6 days of immersion approaching its theoretical value.

$$
\text { strain }=\left(\frac{\text { theoretical value }- \text { experimental value }}{\text { theoretical value }}\right) \times 100
$$

The obtained values suggest substitutions in the atomic positions, which correspond to $\mathrm{Ca}^{2+}$ for $\mathrm{Na}^{+}$or $\mathrm{Mg}^{2+}$, and $\mathrm{Si}^{4+}$ for $\mathrm{P}^{5+}$ due first to the non-stoichiometric $\mathrm{Ca}_{3}\left(\mathrm{PO}_{4}\right)_{2}$-rich $\mathrm{SC}$ phase produced from a solid solution ${ }^{16}$ and second, the crystallization of C-S-P-H hydrogel into SC nanocrystal with average size of a about $70 \mathrm{~nm}$.

The destabilization of original SC lattice leads to the release of the $\mathrm{SiO}_{4}{ }^{4-}$ ions which will later promote the silanol network formation and in conjunction with the absorption of media ions (i.e., $\mathrm{Na}^{+}, \mathrm{Ca}^{2+}, \mathrm{P}^{5+}, \mathrm{Mg}^{2+}$, and $\mathrm{Si}^{4+}$ ) form the new precipitated $\mathrm{SC}$ nanocrystals with a $\mathrm{Ca}_{5-\mathrm{x}}\left(\mathrm{PO}_{4}\right)_{2+\mathrm{x}}\left(\mathrm{SiO}_{4}\right)_{1-\mathrm{x}}$ stoichiometry. Once the new precipitated $\mathrm{SC}$ is established, this provides the conditions for the continuous growth of a layer-by-layer epitaxial apatitic structure through the dynamic ionic exchange with the physiological media. As a result, a dense multi-substituted bone-like apatite layer is built up in a chemically-graded structure due to the decrease of the chemical activity of the $\mathrm{SiO}_{4}{ }^{4-}$ ions through the apatite layer. The formation of $\mathrm{SiO}_{4}{ }^{4-}$ vacancies in the new precipitated $\mathrm{SC}$ structure $\left(\mathrm{Ca}_{5}\left(\mathrm{PO}_{4}\right)_{2} \mathrm{SiO}_{4}\right)$ gives place to the incorporation of either $\mathrm{OH}^{-}$or $\mathrm{CO}_{2}{ }^{3-}$, forming a multi-substituted apatite $\mathrm{Ca}_{10-\mathrm{x}} \mathrm{Na}_{\mathrm{x}}\left(\mathrm{PO}_{4}\right)_{6-\mathrm{y}-2 \mathrm{z}}\left(\mathrm{SiO}_{4}\right)_{\mathrm{y}+\mathrm{z}}\left(\mathrm{CO}_{3}\right)_{\mathrm{x}+\mathrm{z}}(\mathrm{OH})_{2-\mathrm{y}}{ }^{12,55}$ preserving the crystal structure of SC. This stoichiometry has been obtained in the synthesis of silicon-substituted hydroxyapatite that, in some cases, resulted in SC formation ${ }^{12,55}$.

Two phenomena can co-occur, or one precedes the other, but both result in a highly substituted apatite formation that is structurally similar to SC. As its thickness increases, it generates HAp diffraction peaks that do not appear in the SC structure, such as the (002) plane, forming a structure that presents the superposition of the main peaks of both phases and is highly crystalline. 


\subsection{Degradation}

Ionic species concentrations in TRIS and Hank's solutions before and after $120 \mathrm{~h}$ of immersion of SC powders are summarized in Table 2. Both solutions were kept at constant temperature $\left(37^{\circ} \mathrm{C}\right)$ and $\mathrm{pH}(7.4)$ to evaluate the effect of the solution composition on the degradation behavior of as-fabricated SC powder. As observed in Table 2, the TRIS solution contains a very low ions concentration compared to Hank's solution, so it is expected that the presence of certain ions affects the dissolution reaction of the tested material ${ }^{56}$. After the degradation test in the TRIS solution, the leached ions with higher concentrations are $\mathrm{Ca}^{2+}$ and $\mathrm{Na}^{+}$.

For crystalline ceramics, the degradation process starts with the ionic exchange between ionic species in water, particularly $\mathrm{H}^{+}$and alkali components ${ }^{56}$. Therefore, considering the composition of SC and the selective dissolution process of the different ionic species, high concentration values of metallic ions are expected. On the other hand, for Hank's solution, only $\mathrm{Si}$ and $\mathrm{Mg}$ concentrations are higher compared to the composition of the control solution, a similar phenomenon has been associated with the formation of the alteration layer typically in the corrosion of glasses and crystalline ceramics. Three different stages are proposed to describe the degradation mechanism of this kind of materials: stage 1) ionic exchange between the ionic species in the aqueous media and ionic components of the ceramic exposed, stage 2) hydrolysis of network forming species, and stage 3) dissolution of the hydrolyzed species ${ }^{56}$.

According to the current experimental observations, the initial ionic exchange occurs upon the SC ceramics to get in contact with Hank's solution promoting different chemical reactions such as hydration or ion exchange (stage 1). Once the initial contact with Hank's solution takes place, a hydrolysis process occurs to form the C-S-P-H gel, as a result, the ion exchange and different redox reactions still under debate (stage 2). Finally, the dissolution of the different species contained in the C-S-P-H gel gives the condition for the precipitation of a highly substituted apatite with SC-like structure (stage 3). Furthermore, the Si concentration increase in Hank's solution after $120 \mathrm{~h}$ is attributed to the dissolution of silica hydrogel as a result of the incorporation of ions such as $\mathrm{Na}$ and $\mathrm{Ca}$ for the process of the apatite formation. 
It has been reported that the formation of the apatite layer in silicate ceramics follows a dissolution-precipitation mechanism. Once the alkali components are released, the hydrolysis of network silica forming species (silica hydrogel) starts allowing the incorporation of ions from the solution ${ }^{56,57}$.

In the biological aspect, the leached ions concentration in both solutions is among the ranges considered non-cytotoxic. In the case of $\mathrm{Si}^{4+}$ ions, some literature reports have shown that concentrations from 1 to $100 \mathrm{ppm}$ promote osteogenic differentiation of stem cells in the absence of any external osteoinductive factors ${ }^{58}$.

On the other hand, it has been reported that $\mathrm{Si}^{4+}, \mathrm{Ca}^{2+}$, and $\mathrm{Mg}^{2+}$ bioactive ions work together to regulate cell behavior and achieve different effects. The combination of these ions presented both positive and negative synergistic effects with a concentration-dependent manner ${ }^{46}$. An optimal value for osteogenic differentiation was reported with concentration values of 104.69, 13.13, and $33.36 \mathrm{ppm}$ for $\mathrm{Ca}, \mathrm{Mg}$, and $\mathrm{Si}$ ions, respectively. Additionally, an inhibitory effect was found with contents of $119.15,10.99$, and $45.08 \mathrm{ppm}$ for $\mathrm{Ca}, \mathrm{Mg}$, and $\mathrm{Si}$, respectively ${ }^{46}$. Considering that the concentrations measured in Hank's solution are close to the reported values, further biological studies are needed to determine the effect of the ionic release of SC on cell response.

\section{Conclusions}

The apatite-growth mechanism from SC is proposed in this work, based-on the dissolutionprecipitation-crystallization mechanism of the SC phase in a physiological medium. The apatite mineralization process was studied for an SC ceramic through bioactivity assays in Hank's solution and different immersion times. As a consequence of dissolution, Si species are released from the ceramic surface and subsequently combined with $\mathrm{OH}^{-}$ions of Hank's solution medium, leading to the silica-gel polymerization process, which entails the formation of C-S-P-H gel. The adsorption of ionic species within Hank's solution, such as $\mathrm{Ca}$ and $\mathrm{P}$, that combined with the Si present in the gel, promotes the formation of newly formed SC nanocrystals by precipitation. These nanocrystals have an apatite structure and serve as a template for the crystallization process of multi-substituted bone-like apatite. Due to the similarities between the SC and HAp structures, an epitaxial-like growth is here 
confirmed from the apatite layer retaining the SC periodic arrangement. The apatite mineralization mechanism is critical to understand the physical and chemical properties of the bone-like apatite layer, which controls the long-term dissolution/precipitation rate of bioactive materials and their performance in the biological environment.

The obtained results and the proposed mechanism for apatite crystallization have an interest not only from the materials science point of view but also from the biological perspective, as a starting point for further investigations to correlate the structural, morphological and chemical changes observed in the SC ceramics with specific responses at the cell and molecular level.

\section{Funding \\ Conacyt Fordecyt 2018-09-297265 and Fordecyt 2018-296384 \\ Acknowledgments}

The authors thank CONACYT for the student and projects financial support. This project was carried out partially at CENAPROT (LN-299038), LIDTRA (LN-295261 and LN254119) Mexican National Laboratories, Additive Manufacture Consortium and the Spanish MINECO through Project MAT2016 46755-R. Additionally, we thank researchers Josep M. Bassas Scientific and Technological Centers of the University of Barcelona (CCiTUB) for technical support in the XRD and Jose Eleazar Urbina-Alvarez of for technical support in SEM measurements at LIDTRA. Finally, one of the authors thanks Dr. Sergio JiménezSandoval, for his academic support. 


\section{References}

(1) Hench, L. L.; Polak, J. M. Third-Generation Biomedical Materials. Science. 2002, pp 10141017. https://doi.org/10.1126/science.1067404.

(2) Ning, C.; Zhou, L.; Tan, G. Fourth-Generation Biomedical Materials. 2016, 19 (1), 20152016.

(3) Vallet-regí, M. Bio-Ceramics with Clinical Applications; Vallet-Regí, M., Ed.; Wiley, 2014.

(4) Hing, K. A.; Wilson, L. F.; Buckland, T. Comparative Performance of Three Ceramic Bone Graft Substitutes. Spine J. 2007, 7 (4), 475-490. https://doi.org/10.1016/j.spinee.2006.07.017.

(5) Bolger, C.; Jones, D.; Czop, S. Evaluation of an Increased Strut Porosity Silicate - Substituted Calcium Phosphate, SiCaP EP, as a Synthetic Bone Graft Substitute in Spinal Fusion Surgery : A Prospective, Open - Label Study. Eur. Spine J. 2019, No. 0123456789. https://doi.org/10.1007/s00586-019-05926-1.

(6) Wu, C.; Chang, J. A Review of Bioactive Silicate Ceramics. Biomed. Mater. 2013, 8 (3). https://doi.org/10.1088/1748-6041/8/3/032001.

(7) Zhang, W.; Feng, C.; Yang, G.; Li, G.; Ding, X.; Wang, S.; Dou, Y.; Zhang, Z.; Chang, J.; Wu, C. Biomaterials 3D-Printed Scaffolds with Synergistic Effect of Hollow-Pipe Structure and Bioactive Ions for Vascularized Bone Regeneration. 2017, 135, 85-95. https://doi.org/10.1016/j.biomaterials.2017.05.005.

(8) Yan, Y.; Chen, H.; Zhang, H.; Guo, C.; Yang, K.; Chen, K. Biomaterials Vascularized 3D Printed Sca Ff Olds for Promoting Bone Regeneration. 2019, 191 (August 2018), 97-110. https://doi.org/10.1016/j.biomaterials.2018.10.033.

(9) Zhou, Y.; Wu, C.; Xiao, Y. The Stimulation of Proliferation and Differentiation of Periodontal Ligament Cells by the Ionic Products from Ca 7Si 2P 2016 Bioceramics. Acta Biomater. 2012, 8 (6), 2307-2316. https://doi.org/10.1016/j.actbio.2012.03.012.

(10) Shao, H.; Liu, A.; Ke, X.; Sun, M.; He, Y.; Yang, X.; Fu, J.; Zhang, L.; Yang, G.; Liu, Y.; et al. 3D Robocasting Magnesium-Doped Wollastonite/TCP Bioceramic Scaffolds with Improved Bone Regeneration Capacity in Critical Sized Calvarial Defects. 2017, 2941-2951. https://doi.org/10.1039/c7tb00217c.

(11) Couto, R.; Gonçalves, D. A.; Oliveira, E.; Lima, F. F. De; Menezes, L. R. De; Carlos, A.; Thiele, S. 3D Printed Scaffolds as a New Perspective for Bone Tissue Regeneration: 
Literature Review. 2016, No. August, 430-452.

(12) Gomes, S.; Nedelec, J. M.; Jallot, E.; Sheptyakov, D.; Renaudin, G. Silicon Location in Silicate-Substituted Calcium Phosphate Ceramics Determined by Neutron Diffraction. Cryst. Growth Des. 2011, 11 (9), 4017-4026. https://doi.org/10.1021/cg200587s.

(13) Dickens, B.; Brown, W. E. The Crystal Structure of Cas ( P04 ) 2Si04 ( Silieo-Carnotite ). Structure 1971, 7.

(14) Pliego-Cuervo, Y.; Glasser, F. P. Phase Relations and Crystal Chemistry of Apatite and Silicocarnotite Solid Solutions. Cem. concret Res. 1978, 8, 519-523.

(15) Widmer, R.; Gfeller, F.; Armbruster, T. Structural and Crystal Chemical Investigation of Intermediate Phases in the System Ca2SiO4-Ca3(PO4)2-CaNaPO4. J. Am. Ceram. Soc. 2015, 98 (12), 3956-3965. https://doi.org/10.1111/jace.13850.

(16) Rincón-López, J. A.; Hermann-Muñoz, J. A.; Fernández-Benavides, D. A.; Giraldo-Betancur, A. L.; Alvarado-Orozco, J. M.; Muñoz-Saldaña, J. Isothermal Phase Transformations of Bovine-Derived Hydroxyapatite/Bioactive Glass: A Study by Design of Experiments. J. Eur. Ceram. Soc. 2019, 39 (4). https://doi.org/10.1016/j.jeurceramsoc.2018.11.021.

(17) Borsa, R.; Freche, M.; Cosmeleata, G.; Lacout, J.-L.; Ciuca, S. HIGH TEMPERATURE PREPARATION OF SILICON CONTAINING APATITE. U.P.B. Sci. Bull., Ser. B 2008, 70 (3).

(18) Bulina, N. V; Chaikina, M. V; Andreev, A. S.; Lapina, O. B.; Ishchenko, A. V; Prosanov, Y.; Gerasimov, K. B.; Solovyov, L. A. Mechanochemical Synthesis of SiO 44 - -Substituted Hydroxyapatite, Part II - Reaction Mechanism , Structure , and Substitution Limit [\$]. 2014, No. 1, 4810-4825. https://doi.org/10.1002/ejic.201402246.

(19) Bulina, Natalia V; Chaikina, Marina V.;Gerasimov, Konstantin B; Ischenko, Arcady V; Dudina, D. A Novel Approach To the Synthesis of Silicocarnotite. Mater. Lett. 2016, 164, $255-259$.

(20) Duan, W.; Ning, C.; Tang, T. Cytocompatibility and Osteogenic Activity of a Novel Calcium Phosphate Silicate Bioceramic: Silicocarnotite. J. Biomed. Mater. Res. - Part A 2013, 101 A (7), 1955-1961. https://doi.org/10.1002/jbm.a.34497.

(21) Serena, S.; Sainz, M. A.; Caballero, A. Single-Phase Silicocarnotite Synthesis in the Subsystem Ca3(PO4)2-Ca2SiO4. Ceram. Int. 2014, 40 (6), 8245-8252. https://doi.org/10.1016/j.ceramint.2014.01.022. 
(22) Hristov, V.; Radev, L.; Samuneva, B.; Apostolov, G. Organic / Inorganic Bioactive Materials Part I : Synthesis, Structure and in Vitro Assessment of Collagen / Silicocarnotite Biocoatings. 2009, 7 (4). https://doi.org/10.2478/s11532-009-0067-2.

(23) Lu, W.; Duan, W.; Guo, Y.; Ning, C. Mechanical Properties and in Vitro Bioactivity of Ca 5(PO 4) $2 \mathrm{SiO} 4$ Bioceramic. J. Biomater. Appl. 2012, 26 (6), 637-650. https://doi.org/10.1177/0885328210383599.

(24) Lugo, G. J.; Mazón, P.; De Aza, P. N. Material Processing of a New Calcium Silicophosphate Ceramic. Ceram. Int. 2016, $42 \quad$ (1partA), 673-680. https://doi.org/10.1016/j.ceramint.2015.08.164.

(25) Ros-Tárraga, P.; Rabadan-Ros, R.; Murciano, A.; Meseguer-Olmo, L.; De Aza, P. N. Assessment of Effects of Si-Ca-P Biphasic Ceramic on the Osteogenic Differentiation of a Population of Multipotent Adult Human Stem Cells. Materials (Basel). 2016, 9 (12). https://doi.org/10.3390/ma9120969.

(26) Ros-tárraga, P.; Mazón, P.; Rodríguez, M. A.; Meseguer-olmo, L.; Aza, P. N. De. Novel Resorbable and Osteoconductive Calcium Silicophosphate Scaffold Induced Bone Formation. 1-15. https://doi.org/10.3390/ma9090785.

(27) Niu, L. N.; Jiao, K.; Wang, T. Da; Zhang, W.; Camilleri, J.; Bergeron, B. E.; Feng, H. L.; Mao, J.; Chen, J. H.; Pashley, D. H.; et al. A Review of the Bioactivity of Hydraulic Calcium Silicate Cements. J. Dent. 2014, 42 (5), 517-533. https://doi.org/10.1016/j.jdent.2013.12.015.

(28) Barba, A.; Diez-Escudero, A.; Espanol, M.; Bonany, M.; Sadowska, J. M.; Guillem-Marti, J.; Öhman-Mägi, C.; Persson, C.; Manzanares, M. C.; Franch, J.; et al. Impact of Biomimicry in the Design of Osteoinductive Bone Substitutes: Nanoscale Matters. ACS Appl. Mater. Interfaces 2019, 11 (9), 8818-8830. https://doi.org/10.1021/acsami.8b20749.

(29) Saravanapavan, P.; Jones, J. R.; Pryce, R. S.; Hench, L. L. Bioactivity of Gel - Glass Powders in the CaO-SiO 2 System : A Comparison with Ternary ( CaO-P 2 O 5 -SiO 2 ) and Quaternary Glasses ( $\mathrm{SiO} 2$-CaO-P 2 O 5 -Na 2 O ). 2002, 17-19.

(30) Maçon, A. L. B.; Kim, T. B.; Valliant, E. M.; Goetschius, K.; Brow, R. K.; Day, D. E.; Hoppe, A.; Boccaccini, A. R.; Kim, I. Y.; Ohtsuki, C.; et al. A Unified in Vitro Evaluation for ApatiteForming Ability of Bioactive Glasses and Their Variants. J. Mater. Sci. Mater. Med. 2015, 26 (2), 1-10. https://doi.org/10.1007/s10856-015-5403-9.

(31) Ohtsuki, C.; Kokubo, T.; Yamamuro, T. Mechanism of Apatite Formation on CaOSiO2P2O5 
Glasses in a Simulated Body Fluid. J. Non. Cryst. Solids 2005, 143, 84-92. https://doi.org/10.1016/s0022-3093(05)80556-3.

(32) Serena, S.; Caballero, A.; De Aza, P. N.; Sainz, M. A. New Evaluation of the in Vitro Response of Silicocarnotite Monophasic Material. Ceram. Int. 2015, 41 (8), 9412-9419. https://doi.org/10.1016/j.ceramint.2015.03.319.

(33) Takadama, H.; Kim, H. M.; Kokubo, T.; Nakamura, T. Mechanism of Biomineralization of Apatite on a Sodium Silicate Glass: TEM-EDX Study in Vitro. Chem. Mater. 2001, 13 (3), 1108-1113. https://doi.org/10.1021/cm0008718.

(34) Sun, H.; Wu, C.; Dai, K.; Chang, J.; Tang, T. Proliferation and Osteoblastic Differentiation of Human Bone Marrow-Derived Stromal Cells on Akermanite-Bioactive Ceramics. Biomaterials 2006, 27 (33), 5651-5657. https://doi.org/10.1016/j.biomaterials.2006.07.027.

(35) Rincón-López, J. A.; Hermann-Muñoz, J. A.; Giraldo-Betancur, A. L.; De Vizcaya-Ruiz, A.; Alvarado-Orozco, J. M.; Muñoz-Saldaña, J. Synthesis, Characterization and in Vitro Study of Synthetic and Bovine-Derived Hydroxyapatite Ceramics: A Comparison. Materials (Basel). 2018, 9 (3). https://doi.org/10.3390/ma11030333.

(36) Rincón-López, J. A.; Hermann-Muñoz, J. A.; Cinca-Luis, N.; Garrido-Domiguez, B.; GarcíaCano, I.; Guilemany-Casadamon, J. M.; Alvarado-Orozco, J. M.; Muñoz-Saldaña, J. Preferred Growth Orientation of Apatite Crystals on Biological Hydroxyapatite Enriched with Bioactive Glass: A Biomimetic Behavior. Cryst. Growth Des. 2019. https://doi.org/10.1021/acs.cgd.9b00268.

(37) Iso. ISO 10993: Biological Evaluation of Medical Devices - Part 14: Identification and Quantification of Degradation Products from Ceramics; 2002.

(38) Bernal, S.; Botana, F. J.; Calvino, J. J.; López-Cartes, C.; Pérez-Omil, J. A.; RodríguezIzquierdo, J. M. The Interpretation of HREM Images of Supported Metal Catalysts Using Image Simulation: Profile View Images. Ultramicroscopy 1998, 72 (3-4), 135-164. https://doi.org/10.1016/S0304-3991(98)00009-6.

(39) Kirkland, E. J. Advanced Computing in Electron Microscopy: Second Edition; 2010. https://doi.org/10.1007/978-1-4419-6533-2.

(40) Kim, H. M.; Kaneko, H.; Kawashita, M.; Kokubo, T.; Nakamura, T. Mechanism of Apatite Formation on Anodically Oxidized Titanium Metal in Simulated Body Fluid. Key Eng. Mater. 2004, 254-256, 741-744. https://doi.org/10.4028/www.scientific.net/KEM.254-256.741. 
(41) Wu, M.; Wang, T.; Wang, Y.; Wang, H. Ultrafast Bone-like Apatite Formation on Bioactive Tricalcium Silicate Cement Using Mussel-Inspired Polydopamine. Ceram. Int. 2019, 45 (3), 3033-3043. https://doi.org/10.1016/j.ceramint.2018.10.149.

(42) Pan, H.; Liu, Y.; Yao, H. Mystery of the Transformation from Amorphous Calcium Phosphate to Hydroxyapatite W. 2010, 7415-7417. https://doi.org/10.1039/c0cc00971g.

(43) Yu, B.; Liu, J.; Liu, S.; Zhou, F. Pdop Layer Exhibiting Zwitterionicity: A Simple Electrochemical Interface for Governing Ion Permeability. 2010, 5900-5902. https://doi.org/10.1039/c0cc00596g.

(44) Buljan Meić, I.; Kontrec, J.; Domazet Jurašin, D.; Njegić Džakula, B.; Štajner, L.; Lyons, D. M.; Dutour Sikirić, M.; Kralj, D. Comparative Study of Calcium Carbonates and Calcium Phosphates Precipitation in Model Systems Mimicking the Inorganic Environment for Biomineralization. Cryst. Growth Des. 2017, $17 \quad$ (3), 1103-1117. https://doi.org/10.1021/acs.cgd.6b01501.

(45) Andrés, N. C.; D’Elía, N. L.; Ruso, J. M.; Campelo, A. E.; Massheimer, V. L.; Messina, P. V. Manipulation of $\mathrm{Mg} 2+-\mathrm{Ca} 2+$ Switch on the Development of Bone Mimetic Hydroxyapatite. ACS Appl. Mater. Interfaces 2017, $9 \quad$ (18), 15698-15710. https://doi.org/10.1021/acsami.7b02241.

(46) Zhang, M.; Chen, X.; Pu, X.; Liao, X.; Huang, Z.; Yin, G. Dissolution Behavior of $\mathrm{CaO}-\mathrm{MgO}-\mathrm{SiO} 2$-based Multiphase Bioceramic Powders and Effects of the Released Ions on Osteogenesis. J. Biomed. Mater. Res. Part A 2017, No. 24, 1-36.

(47) Kumar, A.; Murugavel, S.; Aditya, A.; Boccaccini, A. R. Mesoporous 45S5 Bioactive Glass: Synthesis,: In Vitro Dissolution and Biomineralization Behavior. J. Mater. Chem. B 2017, 5 (44), 8786-8798. https://doi.org/10.1039/c7tb01738c.

(48) Wu, C.; Han, P.; Xu, M.; Zhang, X.; Zhou, Y.; Xue, G.; Chang, J.; Xiao, Y. Nagelschmidtite Bioceramics with Osteostimulation Properties: Material Chemistry Activating Osteogenic Genes and WNT Signalling Pathway of Human Bone Marrow Stromal Cells. J. Mater. Chem. B 2013, $l$ (6), 876-885. https://doi.org/10.1039/c2tb00391k.

(49) Zhong, J. P.; Greenspan, D. C.; Feng, J. W. A Microstructural Examination of Apatite Induced by Bioglass ${ }^{\circledR}$ in Vitro. J. Mater. Sci. Mater. Med. 2002, 13 (3), 321-326. https://doi.org/10.1023/A:1014075320987.

(50) Liao, S.; Watari, F.; Xu, G.; Ngiam, M.; Ramakrishna, S.; Chan, C. K. Morphological Effects 
of Variant Carbonates in Biomimetic Hydroxyapatite. Mater. Lett. 2007, 61 (17), 3624-3628. https://doi.org/10.1016/j.matlet.2006.12.007.

(51) Jokisaari, J. R.; Wang, C.; Qiao, Q.; Hu, X.; Reed, D. A.; Bleher, R.; Luan, X.; Klie, R. F.; Diekwisch, T. G. H. Particle-Attachment-Mediated and Matrix/Lattice-Guided Enamel Apatite Crystal Growth. ACS Nano 2019, 13 (3), 3151-3161. https://doi.org/10.1021/acsnano.8b08668.

(52) Antonakos, A.; Liarokapis, E.; Leventouri, T. Micro-Raman and FTIR Studies of Synthetic and Natural Apatites. Biomaterials 2007, $28 \quad$ (19), 3043-3054. https://doi.org/10.1016/j.biomaterials.2007.02.028.

(53) Müller, L.; Conforto, E.; Caillard, D.; Müller, F. A. Biomimetic Apatite Coatings-Carbonate Substitution and Preferred Growth Orientation. Biomol. Eng. 2007, 24 (5), 462-466. https://doi.org/10.1016/j.bioeng.2007.07.011.

(54) Dey, A.; Bomans, P. H. H.; Müller, F. A.; Will, J.; Frederik, P. M.; De With, G.; Sommerdijk, N. A. J. M. The Role of Prenucleation Clusters in Surface-Induced Calcium Phosphate Crystallization. Nat. Mater. 2010, 9 (12), 1010-1014. https://doi.org/10.1038/nmat2900.

(55) Mostafa, N. Y.; Hassan, H. M.; Mohamed, F. H. Sintering Behavior and Thermal Stability of $\mathrm{Na}+$, SiO44- and CO32- Co-Substituted Hydroxyapatites. J. Alloys Compd. 2009, 479 (1-2), 692-698. https://doi.org/10.1016/j.jallcom.2009.01.037.

(56) Frankel, G. S.; Vienna, J. D.; Lian, J.; Scully, J. R.; Gin, S.; Ryan, J. V.; Wang, J.; Kim, S. H.; Windl, W.; Du, J. A Comparative Review of the Aqueous Corrosion of Glasses, Crystalline Ceramics, and Metals. npj Mater. Degrad. 2018, 2 (1). https://doi.org/10.1038/s41529-0180037-2.

(57) White, W. B. Theory of Corrosion of Glass and Ceramics. Corros. Glas. Ceram. Supercond. 1992, No. 2, 2-28.

(58) Gaharwar, A. K.; Mihaila, S. M.; Swami, A.; Patel, A.; Sant, S.; Reis, R. L.; Marques, A. P.; Gomes, M. E.; Khademhosseini, A. Bioactive Silicate Nanoplatelets for Osteogenic Differentiation of Human Mesenchymal Stem Cells. Adv. Mater. 2013, 25 (24), 3329-3336. https://doi.org/10.1002/adma.201300584. 


\section{Figure caption}

Figure 1. Microstructural characteristics at different magnifications of SC ceramics $(a, b)$ before and after (c,d) 6 days of immersion in Hank's solution.

Figure 2. Morphological features of the apatite layer grown on SC ceramics after 14 days of immersion in Hank's solution. a) Ceramic's surface covered by plate-like crystals observed with more detail in (b, d). c) Cross-section of the apatite layer using a backscatter electron detector, suggesting a composition gradient along with the layer due to the contrast.

Figure 3. SEM micrographs at the $(\mathrm{a}, \mathrm{b})$ surface and $(\mathrm{c}, \mathrm{d})$ cross-section of the apatite layer formed on SC ceramics after 28 days of exposure to Hank's solution.

Figure 4a. Cross-section of SC ceramics after 6 days of immersion in Hank's solution showing the apatite layer growing at the interface and inside the internal pores.

Figure 4b. Cross-section of SC ceramics after 28 days of immersion in Hank's solution showing the apatite layer growing at the I) interface and (II) filling the internal pores.

Figure 5. XRD pattern of a) SC ceramics after 0, 6, 14, and 28 days of immersion and XRD pattern of HAp for comparative purposes. b) Content (wt.\%) and crystallite size of the apatite grown on SC ceramics after different immersion periods and c) strain and crystallite size in the remaining SC phase.

Figure 6. a) High-resolution TEM image and b) SAED pattern of the same SC zone, before bioactivity test.

Figure 7. a, b) High-resolution TEM images, (inset a) FFT and c) inverse FFT of SC before bioactivity test.

Figure 8. High-resolution TEM images of SC after 6 days of exposure in Hank's solution, showing in a) morphology of the particles composed by a C-S-P-H gel and b) crystalline zones. c) FFT image of the crystalline zone in b.

Figure 9. High-resolution TEM images of different areas of SC particles after 28 days of immersion showing $a$ ) a general view, $b$ ) elongated and overlapped crystals and $c$ ) dense crystal. 
Figure 10. High-resolution TEM images of bone-like apatite grown from SC after 28 days of exposure in Hank's solution, showing in a) the microstructure of the apatite particles and inverse FFT (inset), b) highly crystalline zones and c) SAED pattern of a).

Figure 11. Top panel: a) atomic model of the interface between SC and apatite oriented along the coherent zone axes found from experimental images, b-g) schematics of the different stages of apatite growth modeled and resulting HRTEM simulated images. Bottom panel: on the left, inverse FFT filtered HRTEM image from the sample before immersion, and on the right, inverse FFT filtered HRTEM image of the sample after immersion. The trend in contrast change in the simulations with the increasing apatite thickness matches the observed experimental contrast.

Figure 12. Raman spectra of SC ceramics after different immersion periods in Hank's solution and Raman spectra of HAp for comparative purposes.

Figure 13. Schematic representation of the mechanism of bone-like apatite formation from SC bioceramics 


\section{Table caption}

Table 1. EDX measurements of SC ceramics before and after 6, 14, and 28 days of immersion in Hank's solution.

Table 2. The concentration of ionic species before and after degradation test of SC in TRIS and Hank's solutions. 
Table 1

\begin{tabular}{cccccccc}
\hline \multicolumn{7}{c}{ SEM /EDX (wt.\%) } \\
\hline Sample & $\mathbf{O}$ & $\mathbf{N a}$ & $\mathbf{M g}$ & $\mathbf{S i}$ & $\mathbf{P}$ & $\mathbf{C l}$ & $\mathbf{C a}$ \\
\hline Control & $40.608 \pm 0.117$ & $3.388 \pm 0.058$ & $0.195 \pm 0.023$ & $2.148 \pm 0.020$ & $17.412 \pm 0.050$ & & $36.217 \pm 0.087$ \\
6 days & $35.654 \pm 6.623$ & $2.924 \pm 0.965$ & $1.408 \pm 1.122$ & $1.615 \pm 0.467$ & $19.683 \pm 3.387$ & $0.112 \pm 0.097$ & $38.604 \pm 4.437$ \\
14 days & $41.515 \pm 2.486$ & $1.618 \pm 0.243$ & $3.777 \pm 0.309$ & $0.159 \pm 0.131$ & $21.741 \pm 0.496$ & $1.126 \pm 0.246$ & $30.065 \pm 2.598$ \\
28 days & $37.030 \pm 0.941$ & $2.180 \pm 0.422$ & $1.821 \pm 0.330$ & $0.452 \pm 0.300$ & $23.800 \pm 0.793$ & $1.971 \pm 0.312$ & $34.896 \pm 0.941$ \\
\hline
\end{tabular}


Table 2

\begin{tabular}{ccc|cc}
\hline \multicolumn{2}{c|}{ Tris solution } & \multicolumn{2}{c}{ Hank's solution } \\
\hline Ionic species & $\begin{array}{c}0 \text { hours } \\
{[\mathrm{ppm}]}\end{array}$ & $\begin{array}{c}120 \text { hours } \\
{[\mathrm{ppm}]}\end{array}$ & $\begin{array}{c}0 \text { hours } \\
{[\mathrm{ppm}]}\end{array}$ & $\begin{array}{c}120 \text { hours } \\
{[\mathrm{ppm}]}\end{array}$ \\
\hline$[\mathrm{Ca}]$ & $0.514 \pm 0.118$ & $129.349 \pm 5.660$ & $51.513 \pm 1.583$ & $36.834 \pm 0.655$ \\
{$[\mathrm{Si}]$} & $0.142 \pm 0.004$ & $13.864 \pm 0.011$ & $0.321 \pm 0.156$ & $6.791 \pm 0.106$ \\
{$[\mathrm{Mg}]$} & $0.175 \pm 0.039$ & $13.419 \pm 0.281$ & $20.148 \pm 0.416$ & $23.831 \pm 0.670$ \\
{$[\mathrm{P}]$} & $0.709 \pm 0.189$ & $11.231 \pm 1.173$ & $25.791 \pm 0.682$ & $3.461 \pm 2.633$ \\
{$[\mathrm{Na}]$} & $5.653 \pm 3.763$ & $45.977 \pm 2.527$ & $3298.687 \pm 50.358$ & $2488.394 \pm 28.296$ \\
\hline
\end{tabular}




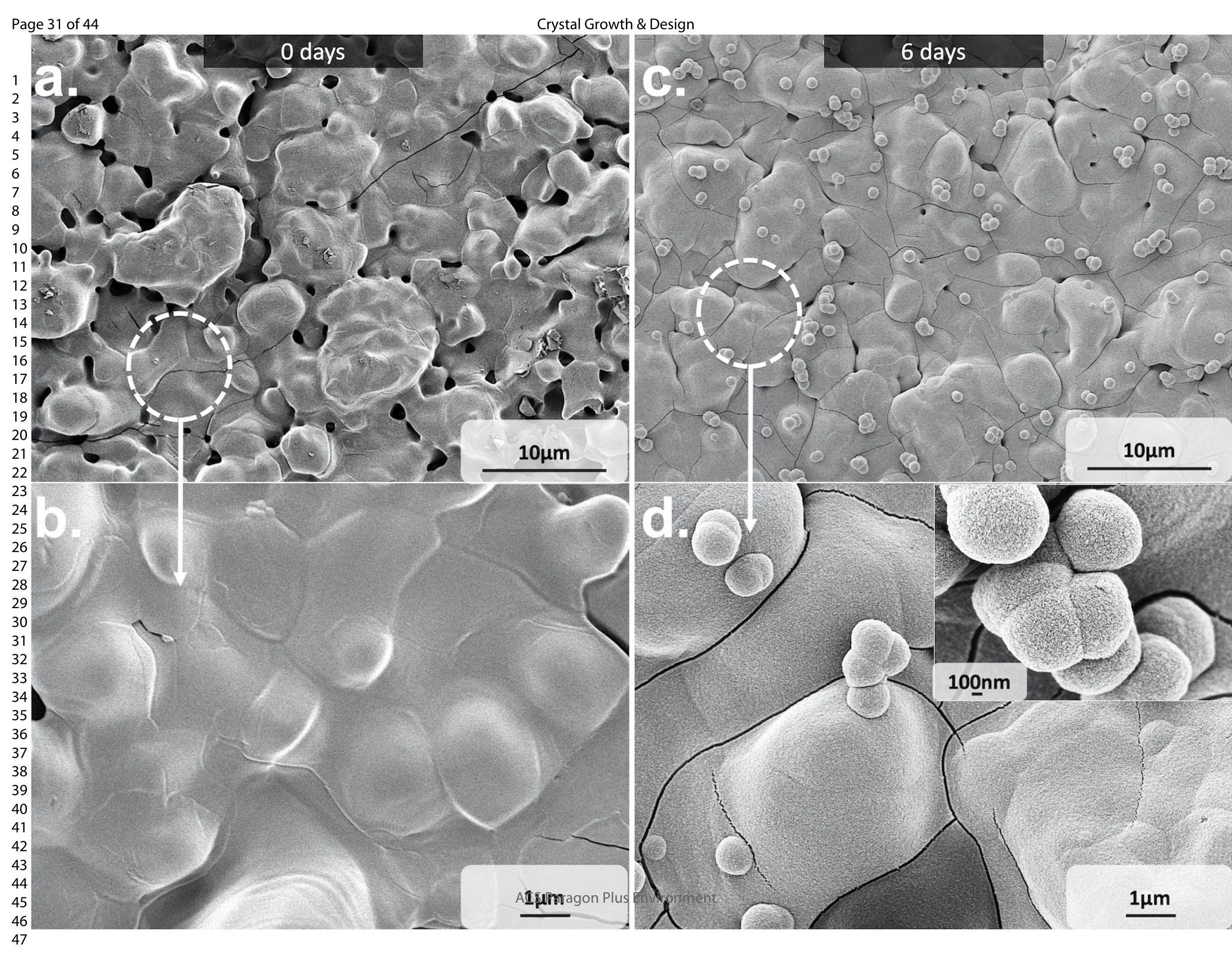



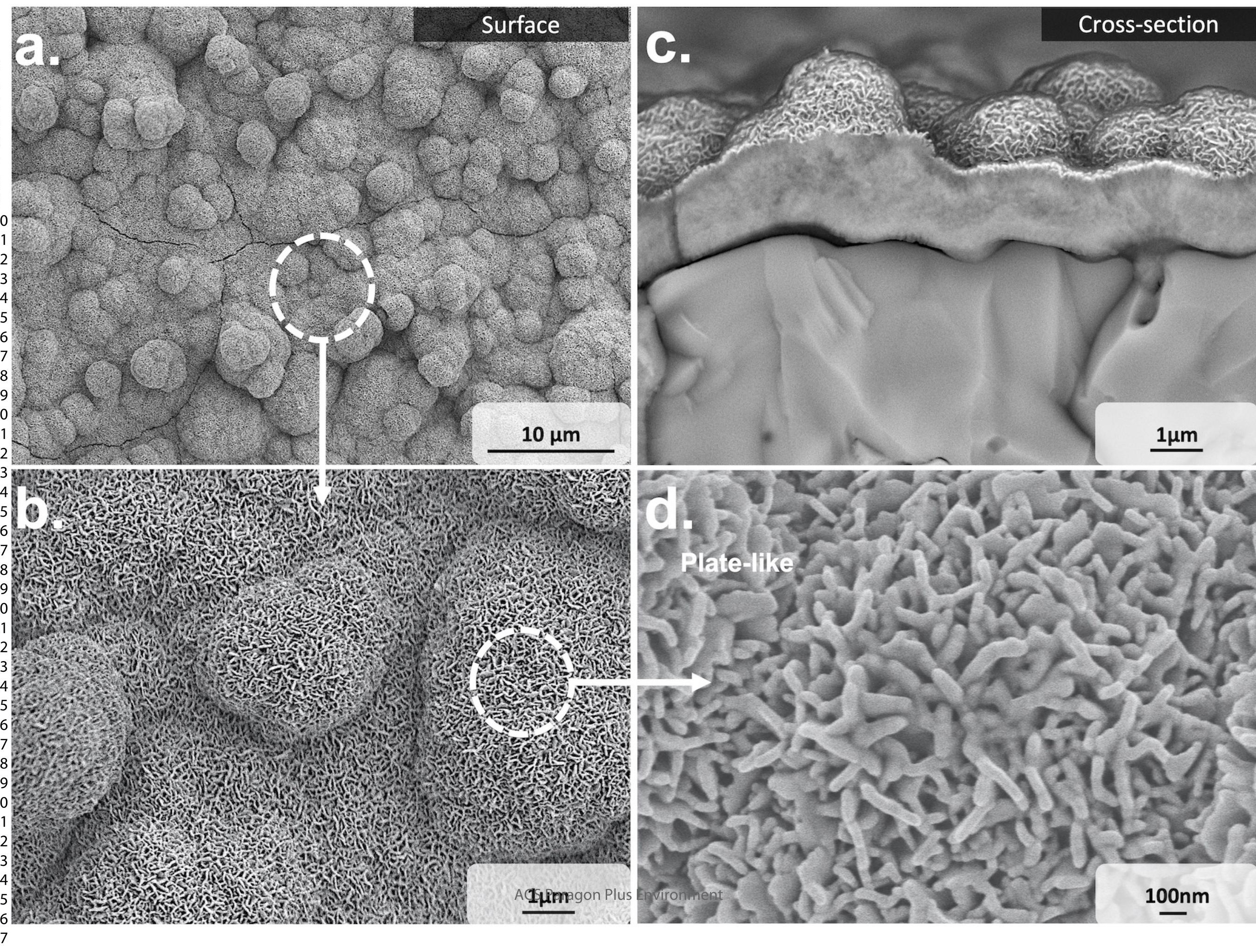


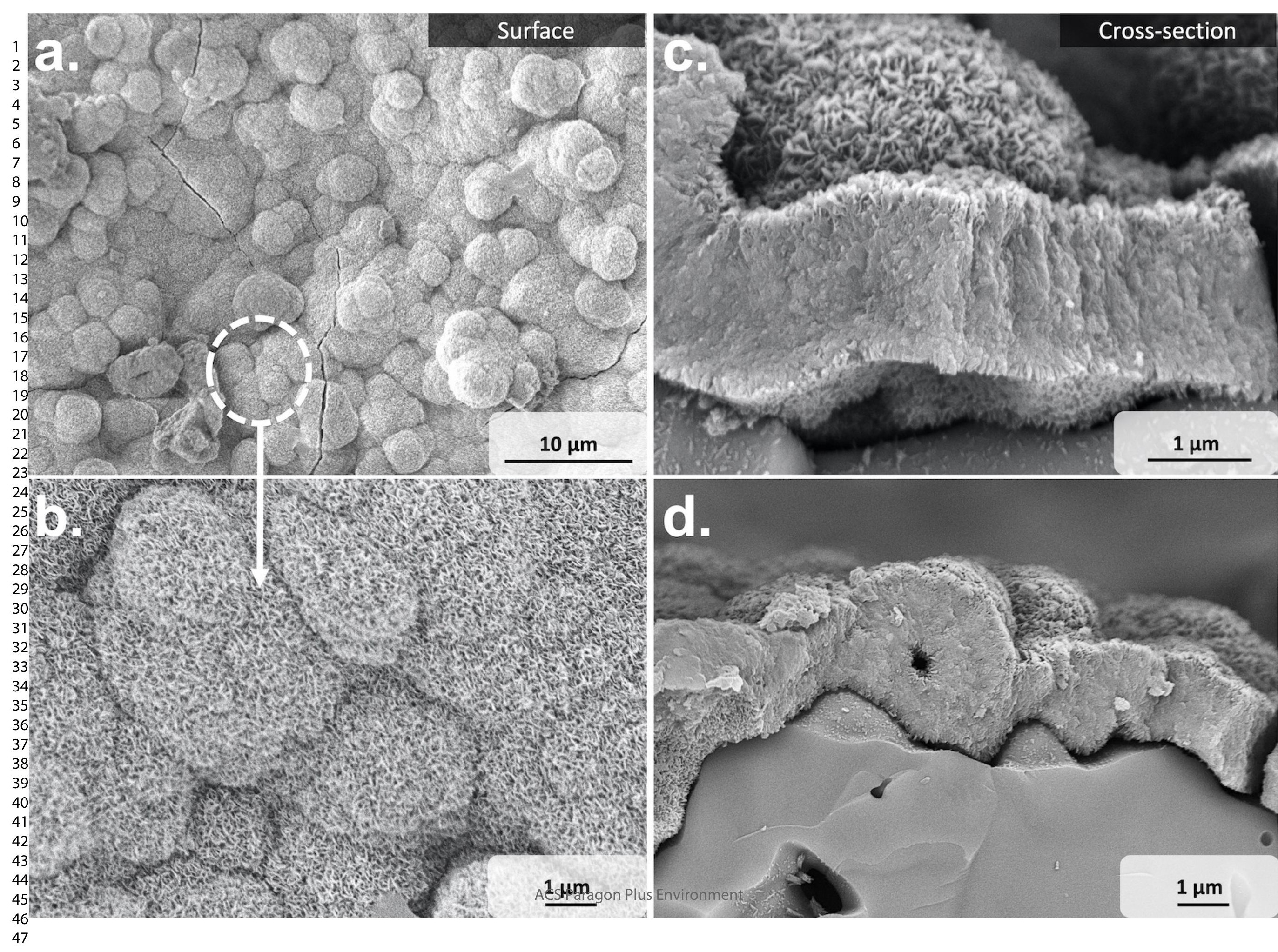




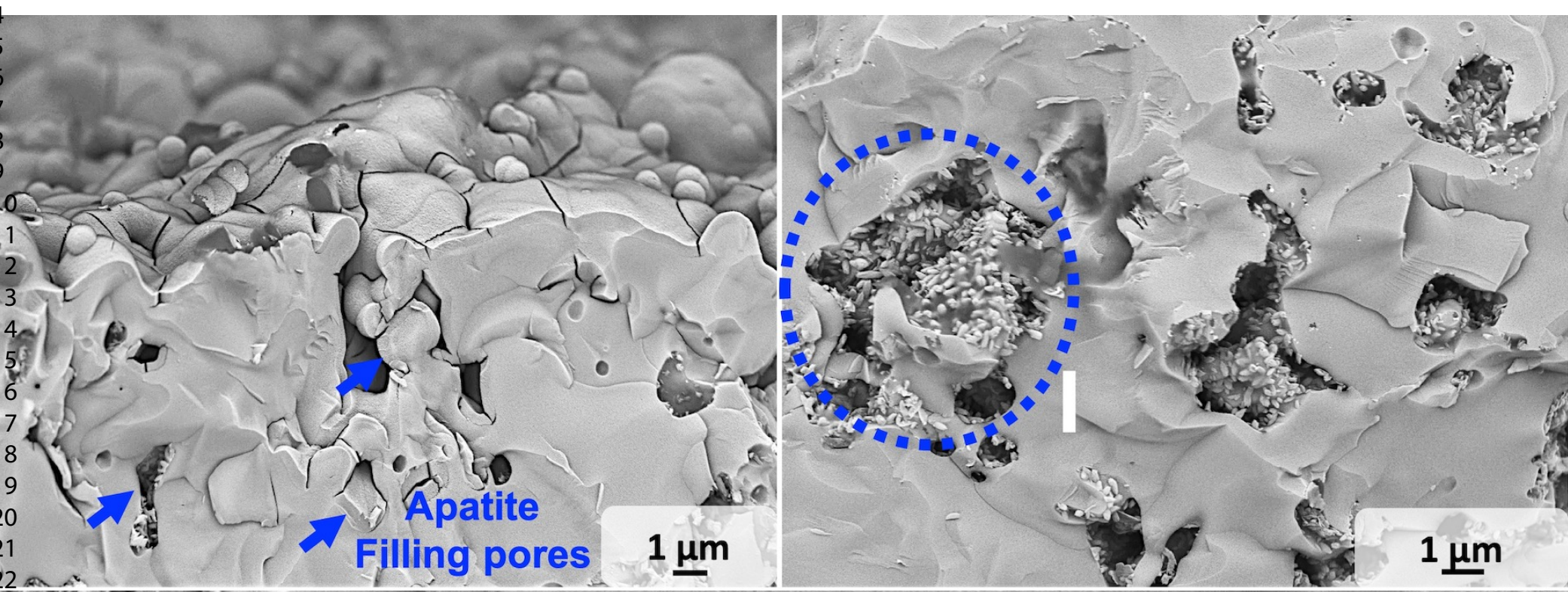

\section{2.}

27

28

$30-182$

(1)

35

$13 p=$

30102

36

37

38

39

40

125

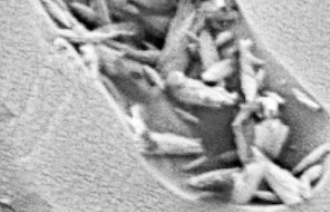

Filling pores $1 \underline{\mu m}$

쓰
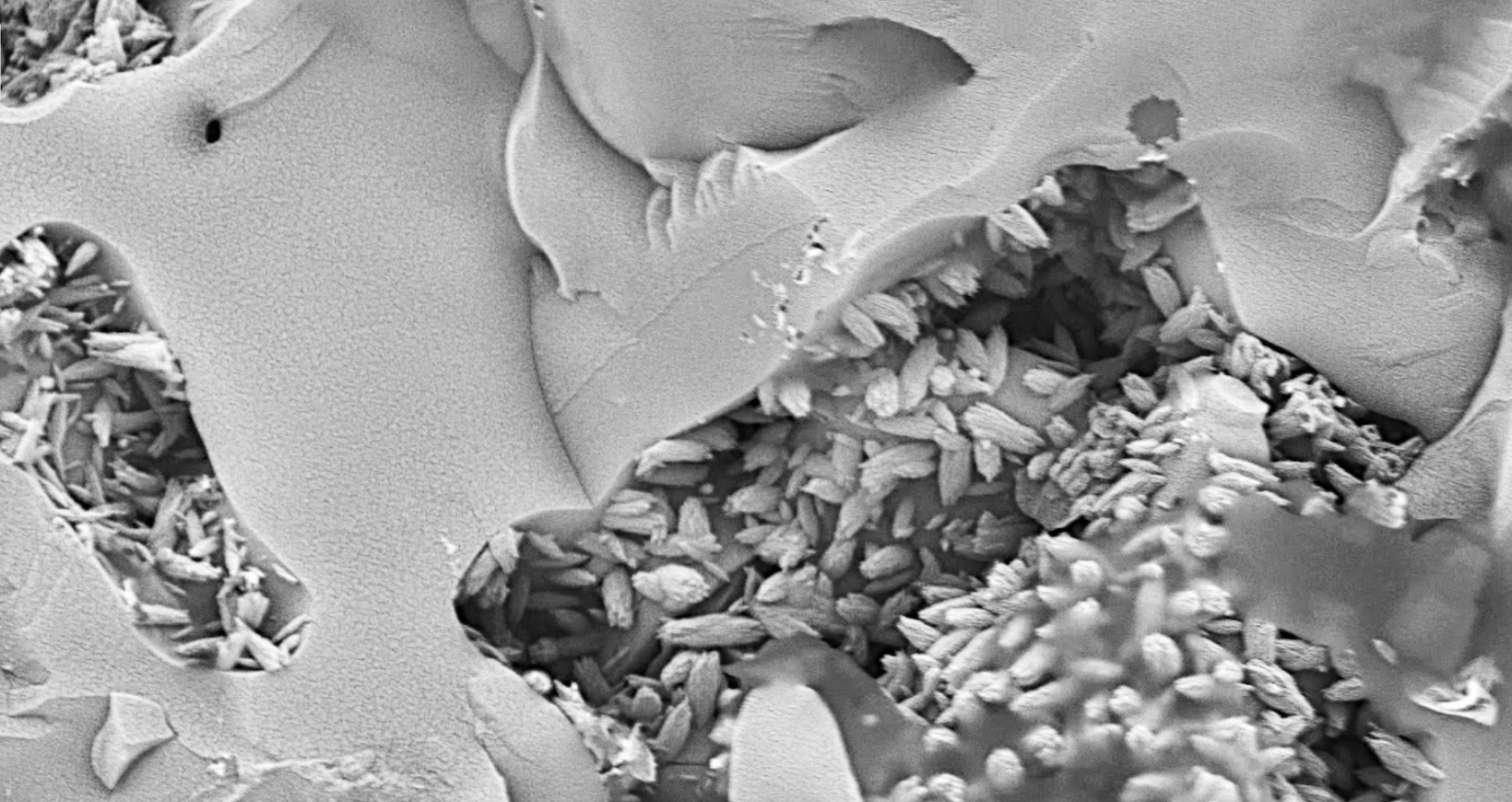

2 as $\therefore(3+5)=1$
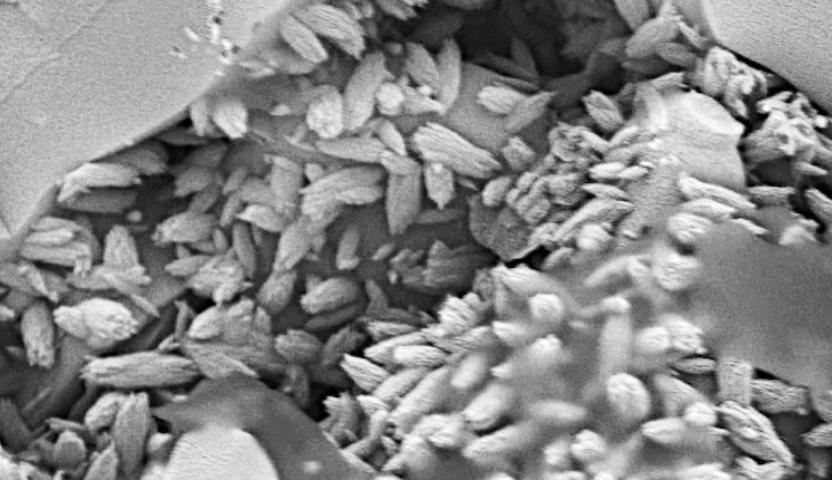

of:

$1=$

44

45

46

47

48

4

51

52

53

54

55

$1-30$ metses

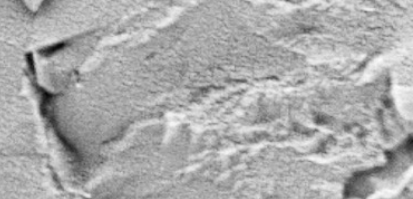

$\rightarrow$ freal ase

(3) $1 \mathrm{i}^{2}$

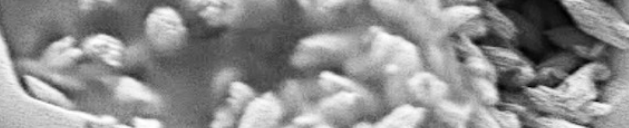
$(-2, y)$ ints

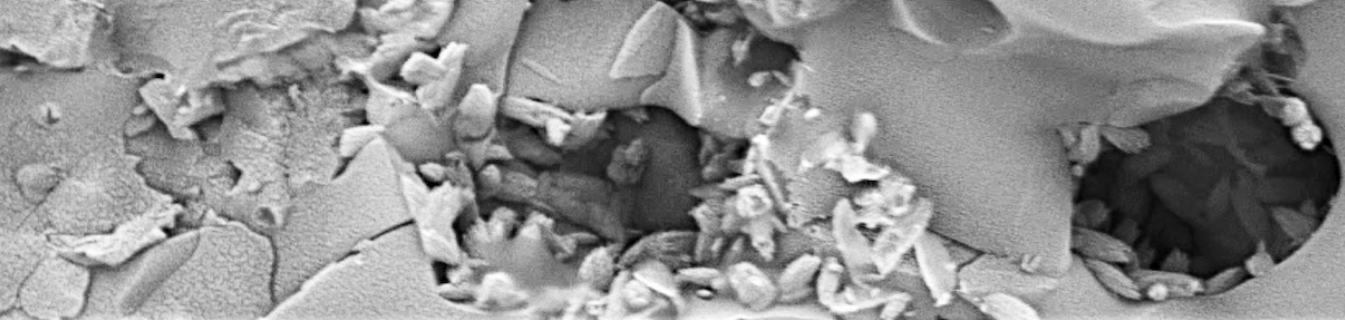




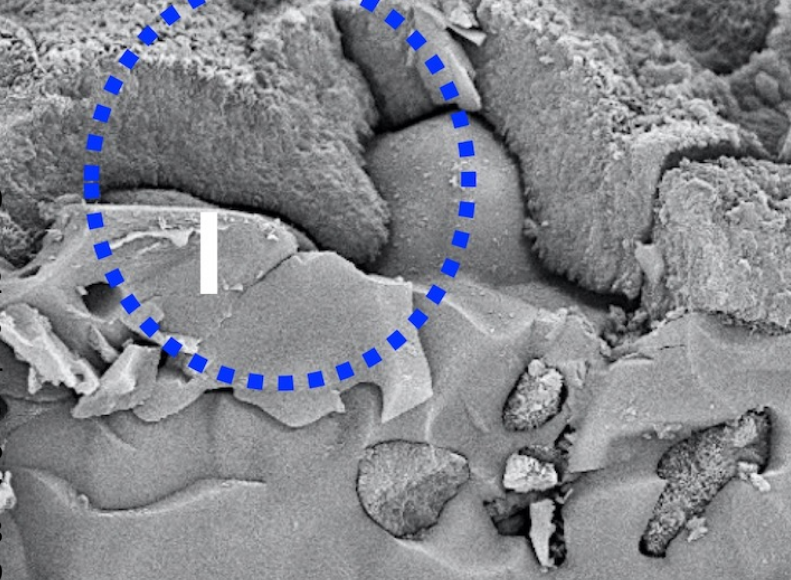

1
2
2
2
2
2
2
2

2
2
2
2
2
2
2
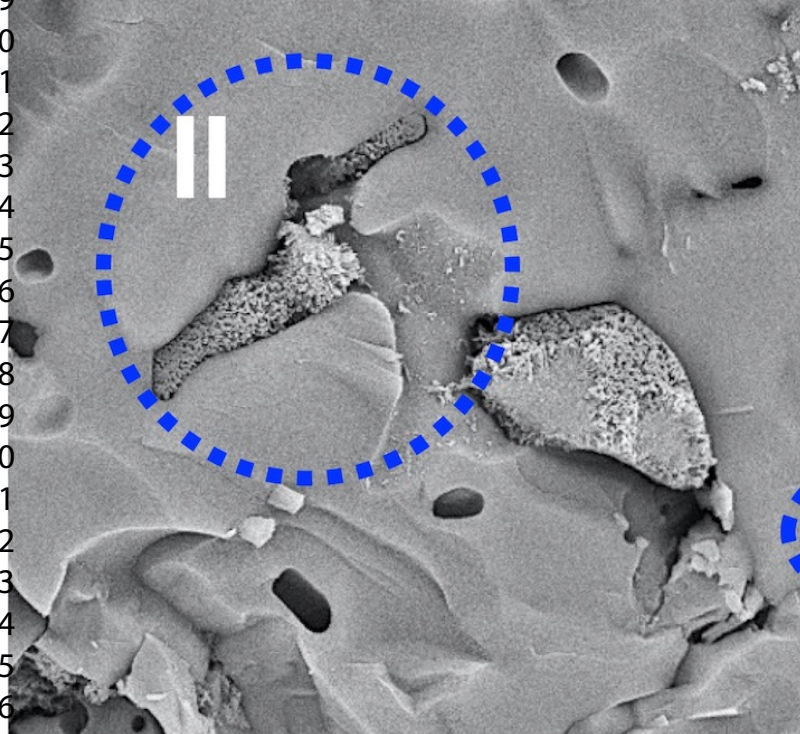

3

3
3
4
4
4
4
4
4
4
4
4
4
5
5
5
5
5
5
5
5
5
5
6
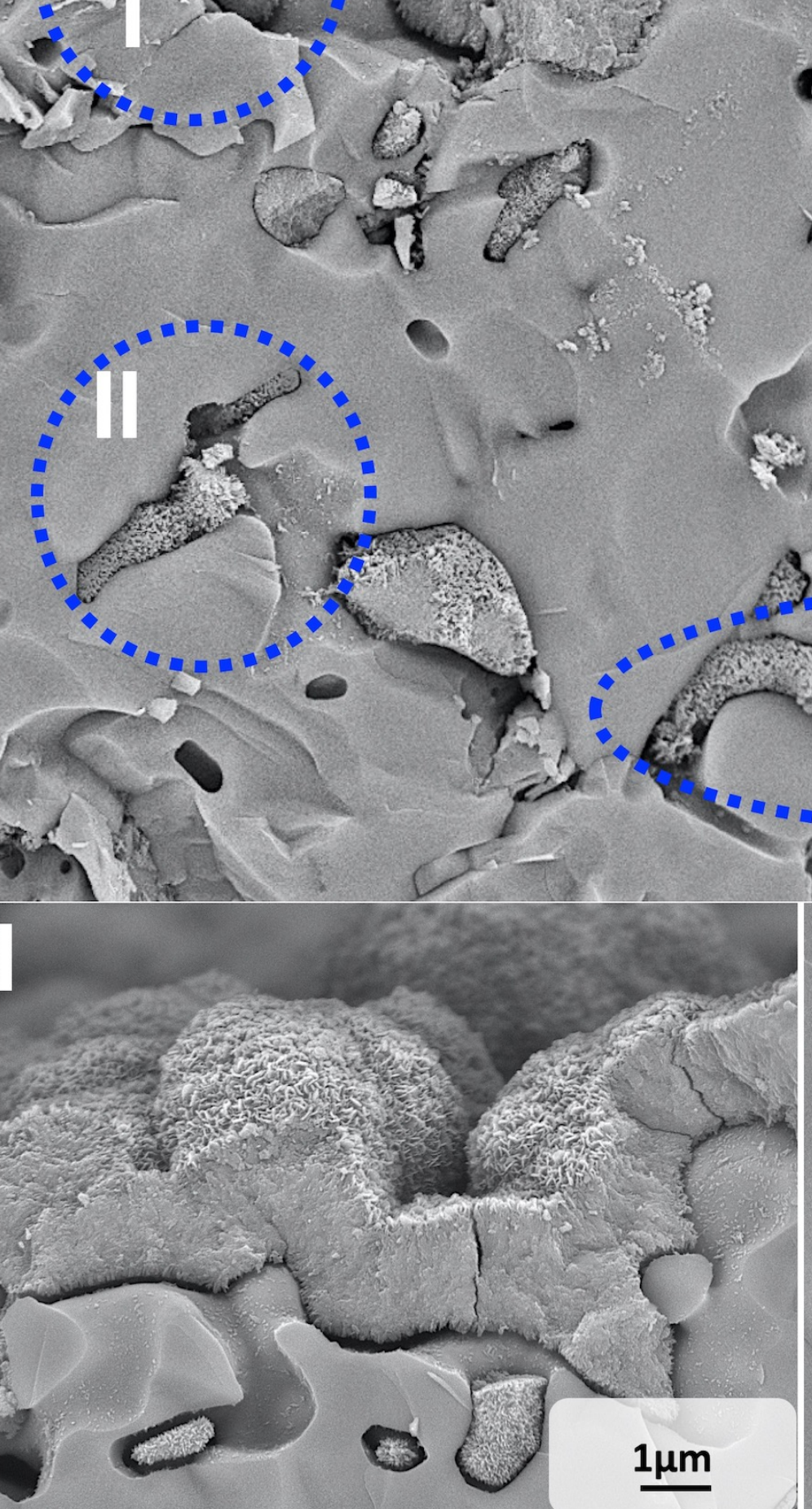
6

\section{Apatite}

(2) filled pores
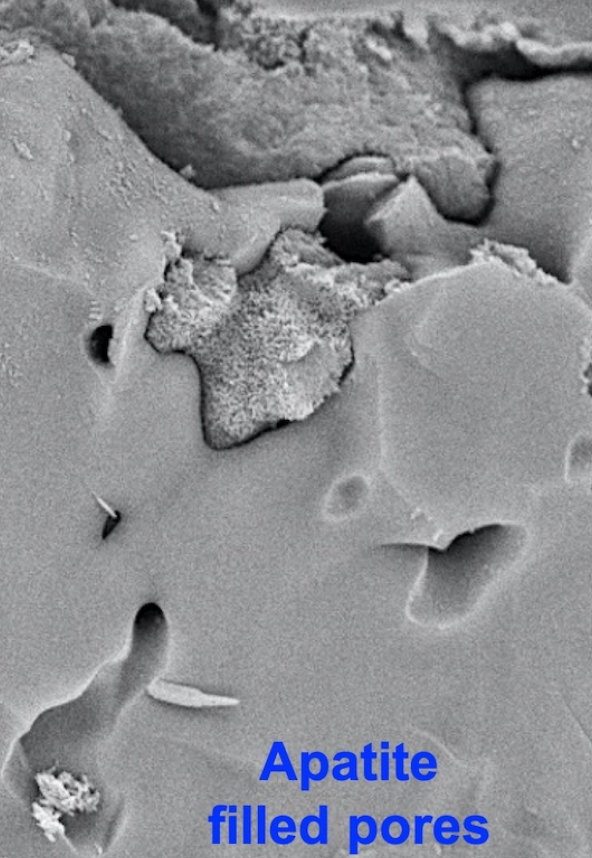

$\int_{1} x^{2}$ s.

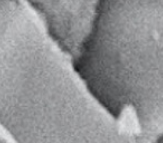

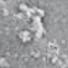
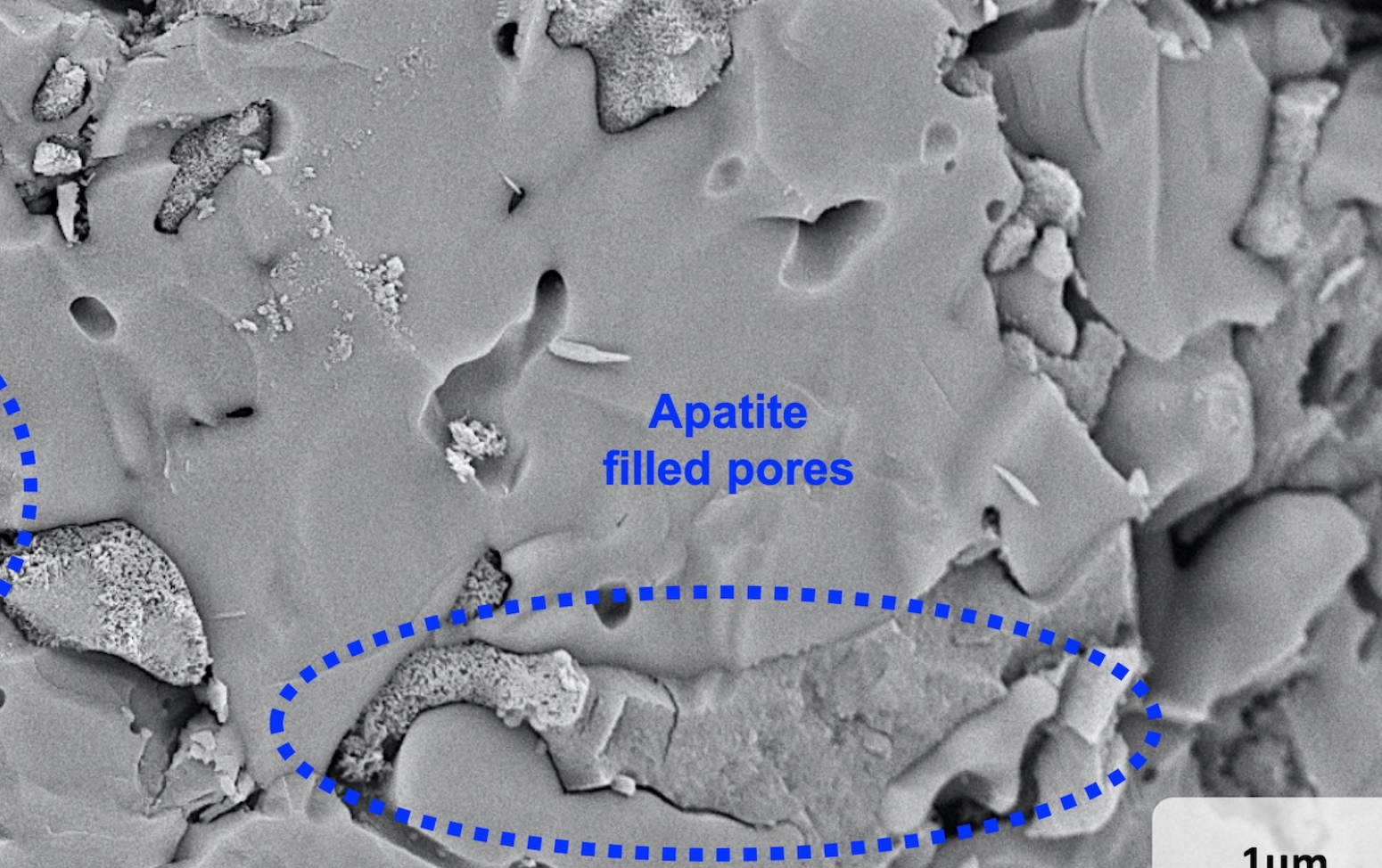

\section{$\underline{1 \mu \mathrm{m}}$}

\footnotetext{
ACS Paragon Plus Environment
} 

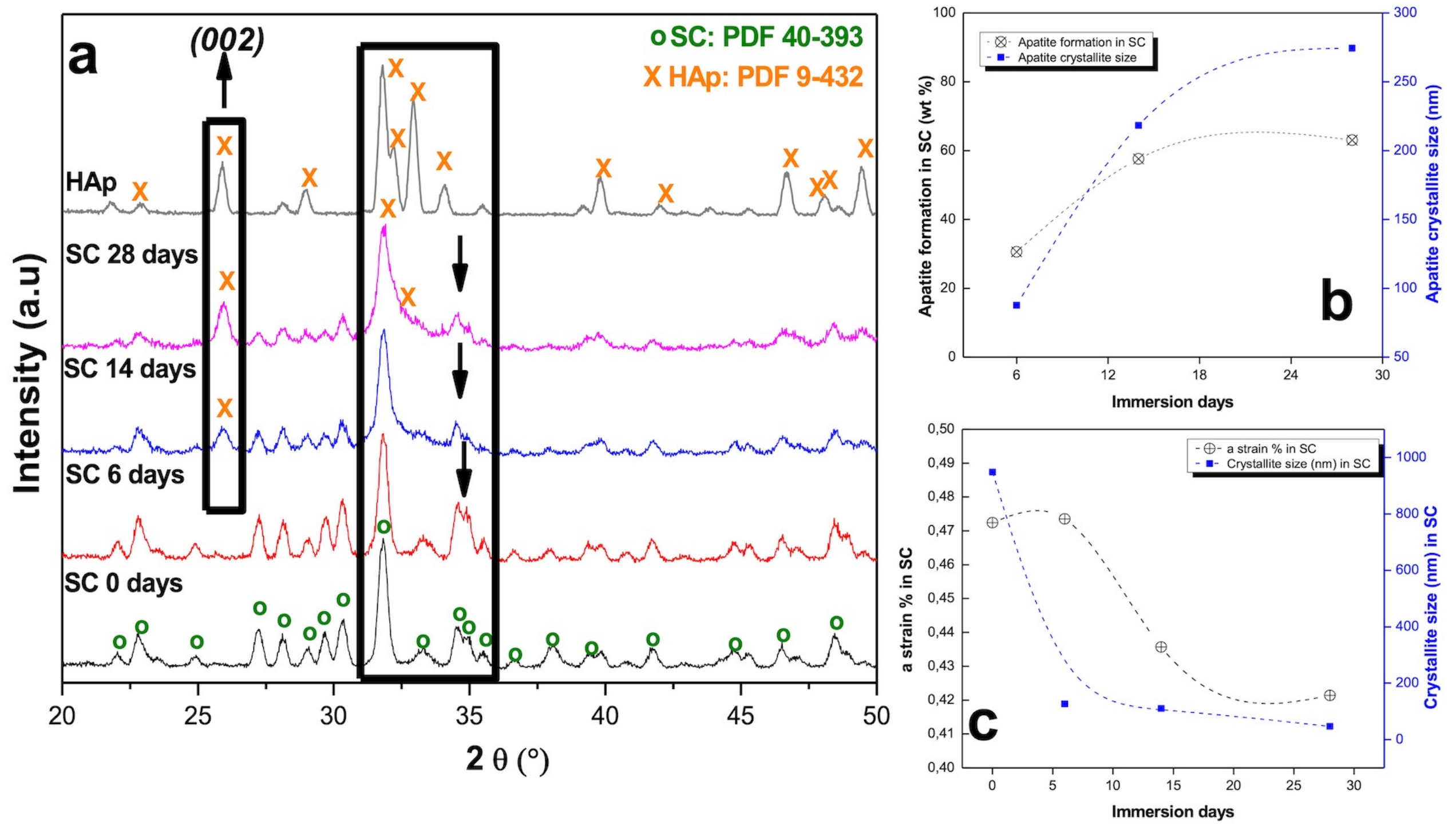

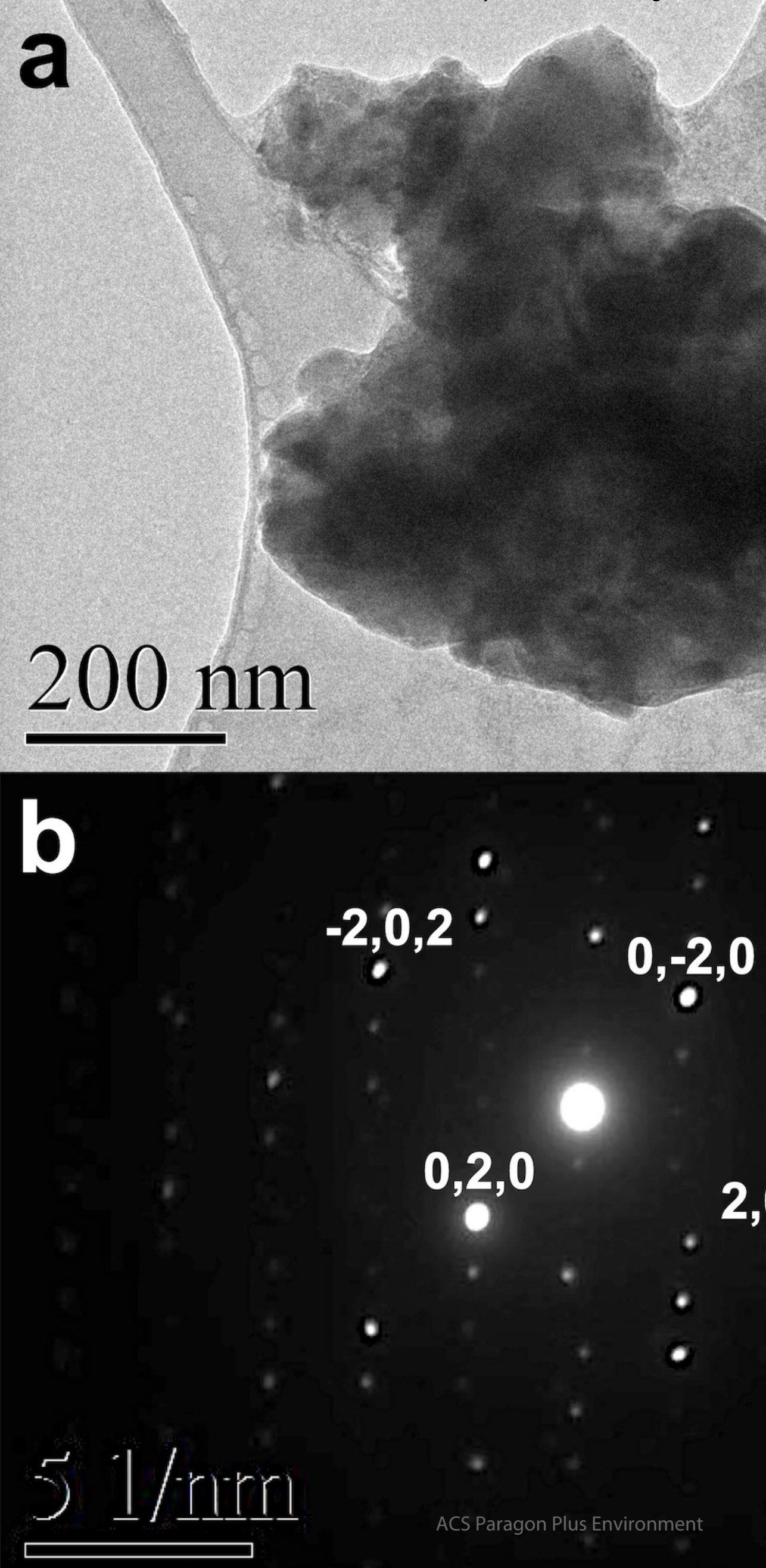

\section{$0,2,0$}

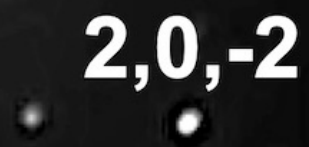



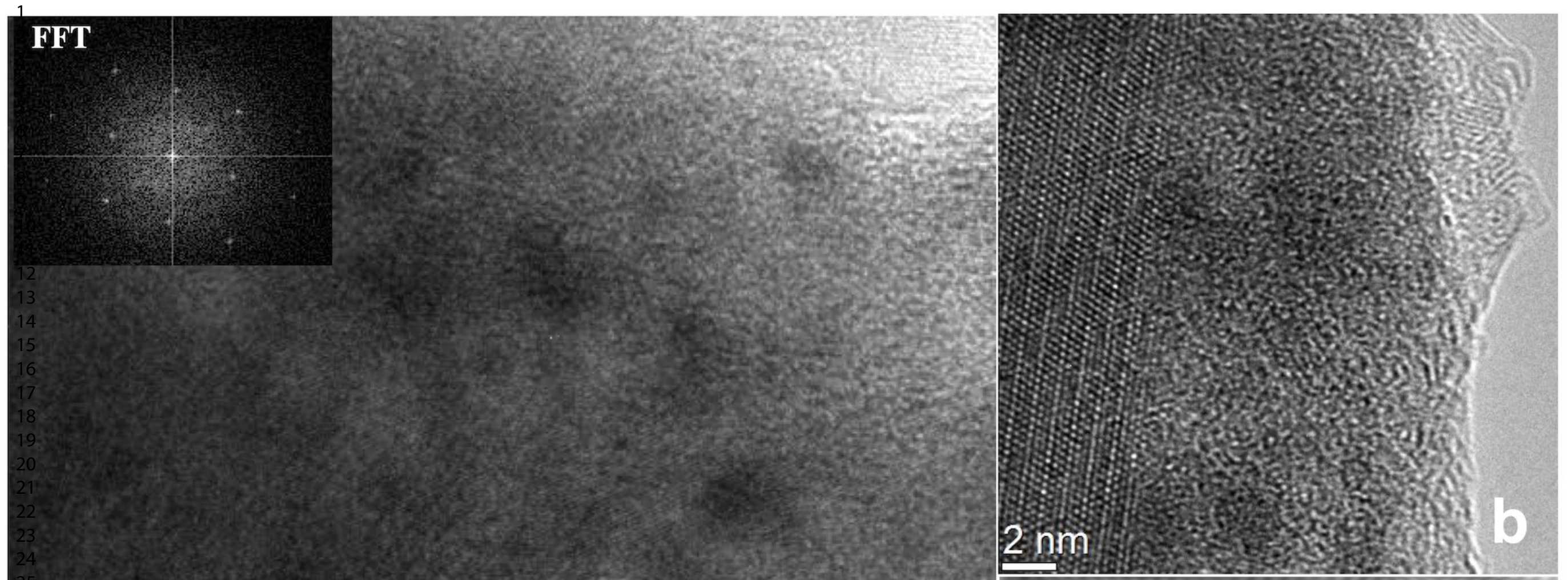

.

$10 \mathrm{~nm}$

Inverse FIFT 
b
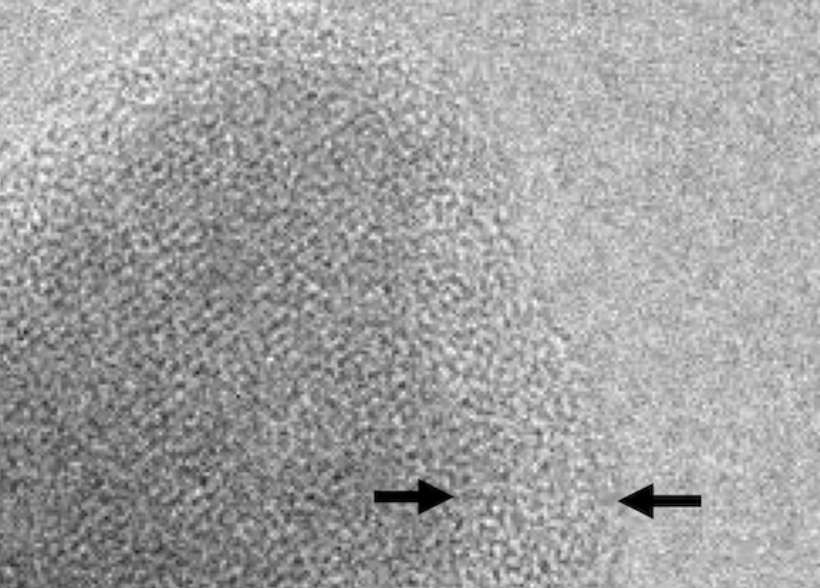

stos 450
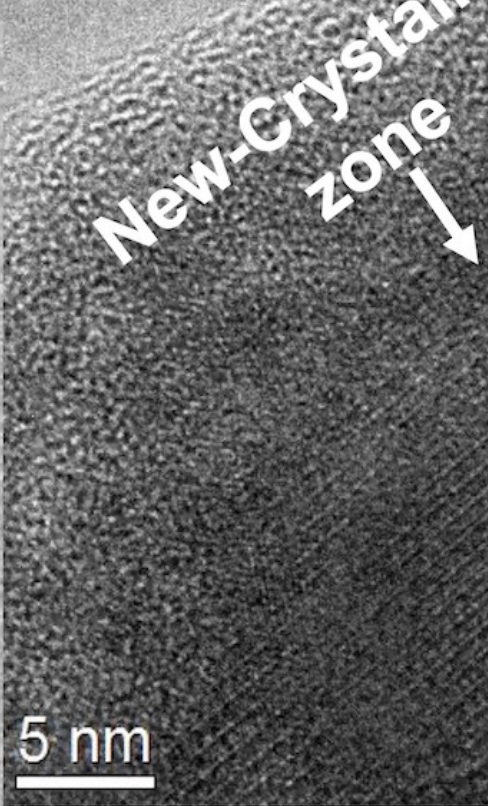

$5 \mathrm{~nm}$

\section{C-S-P-H gel}

C

$10 \mathrm{~nm}$

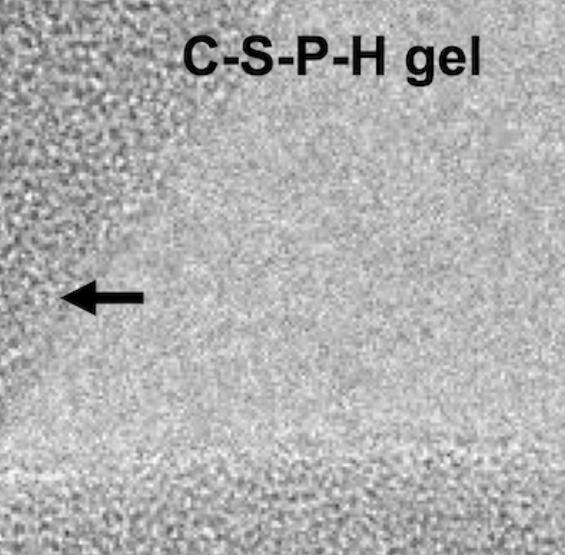




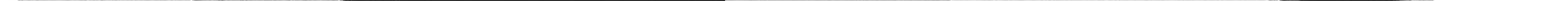




\section{.

2

(n)

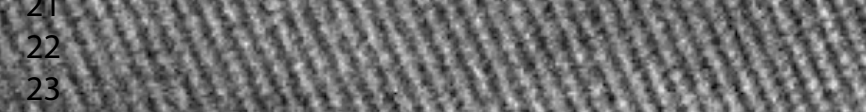

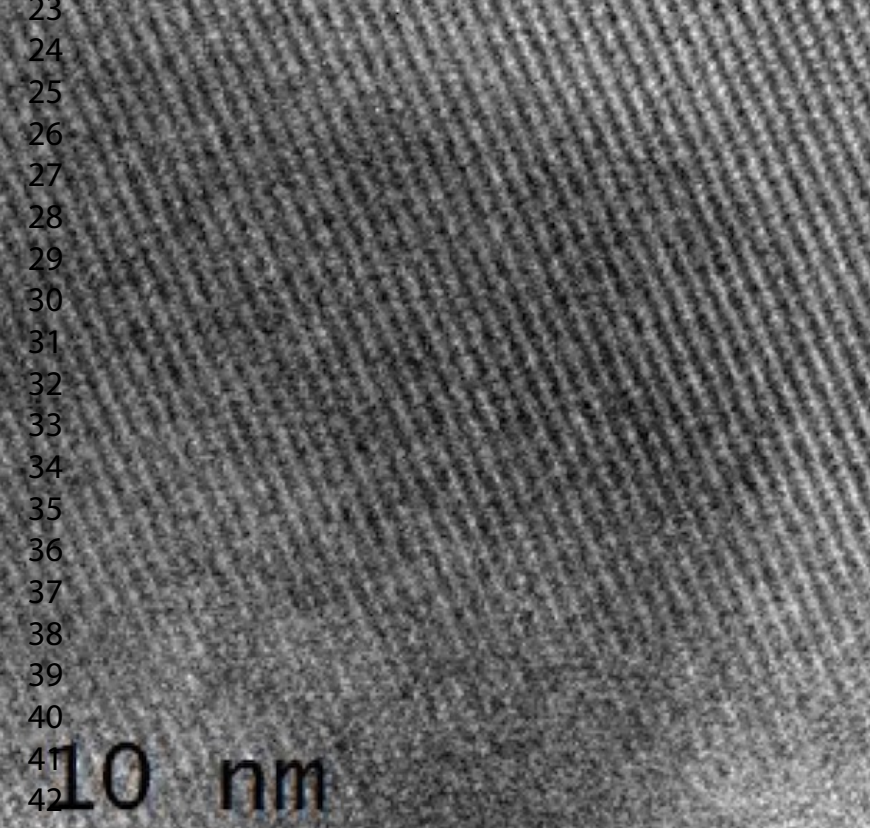

ando $\mathrm{nm}$

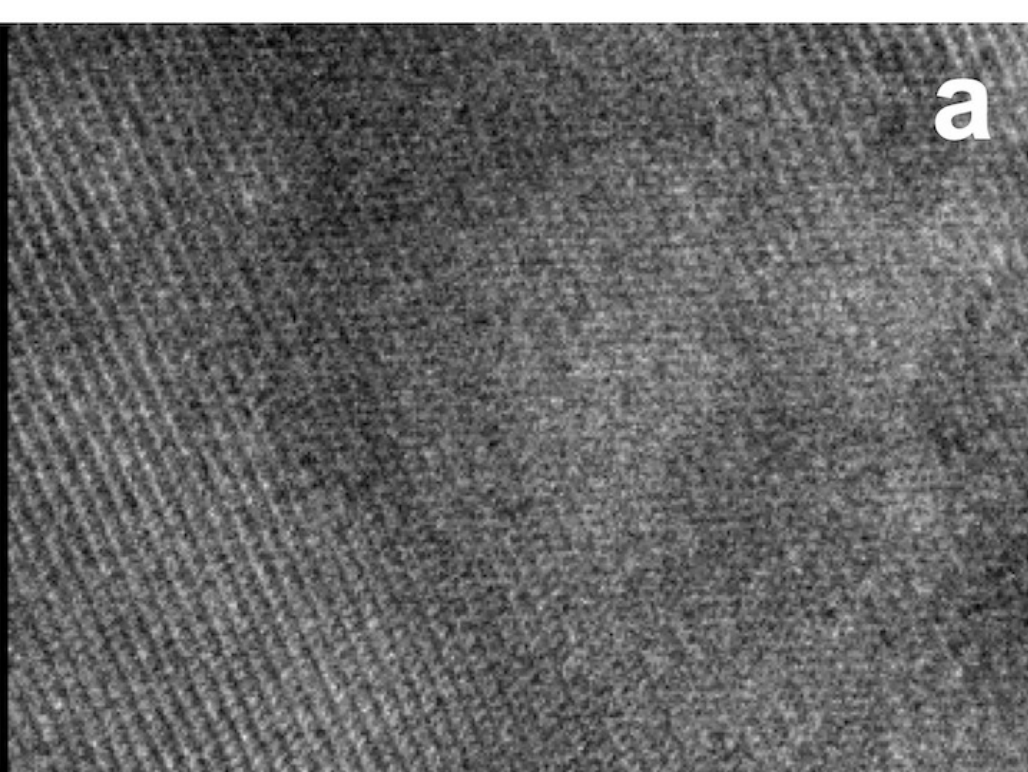
In)
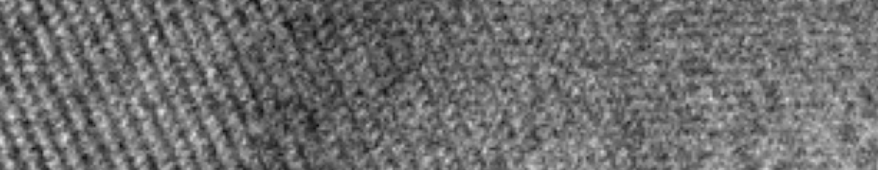
HW

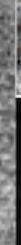
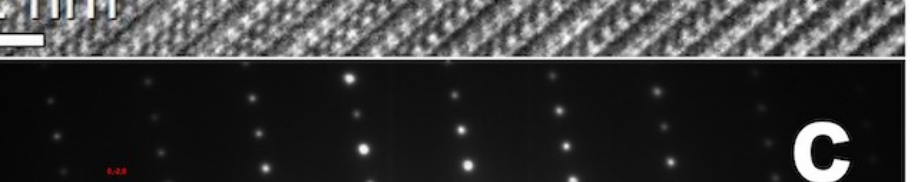


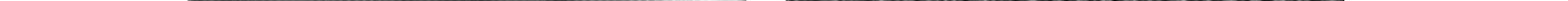




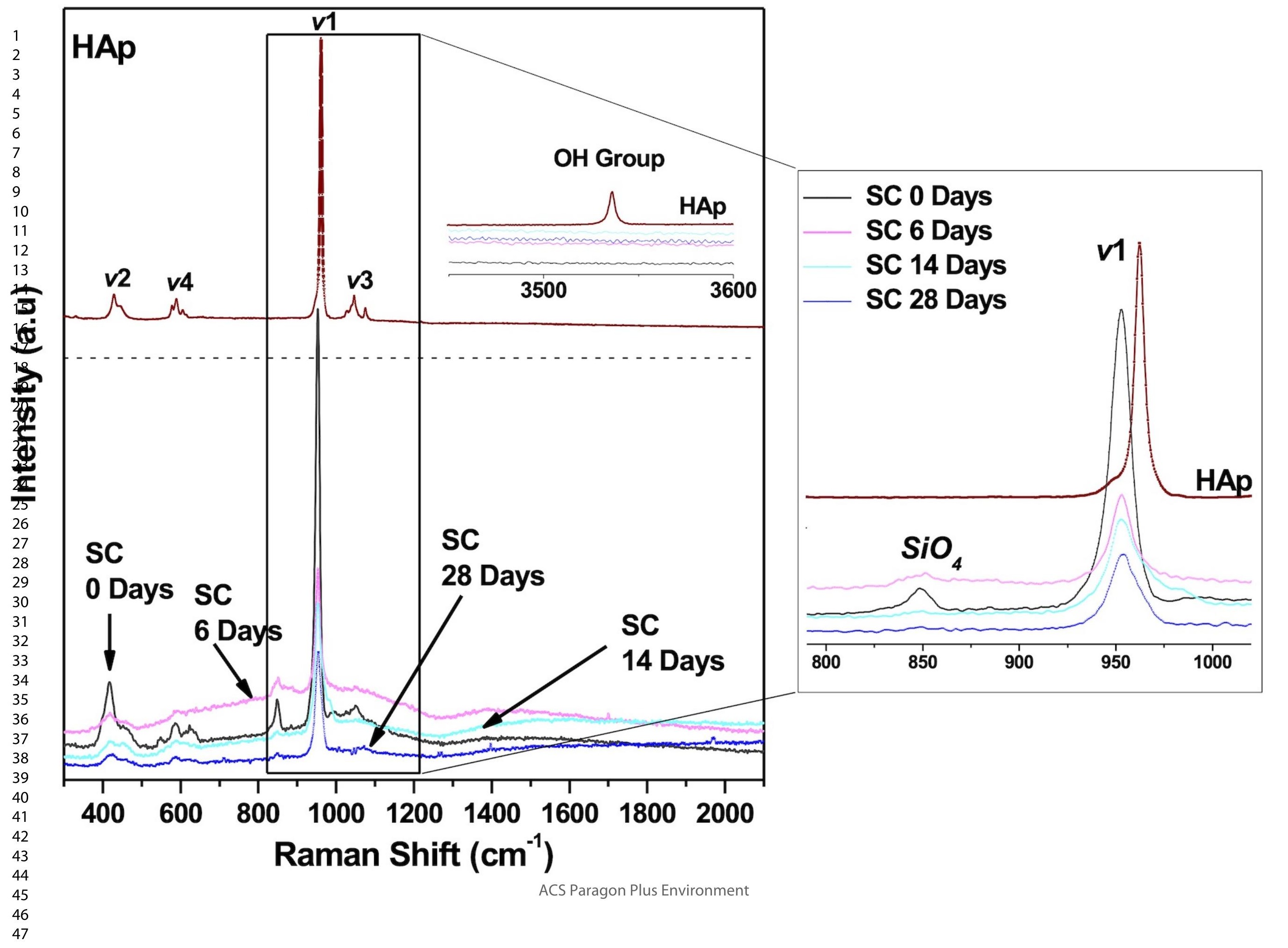




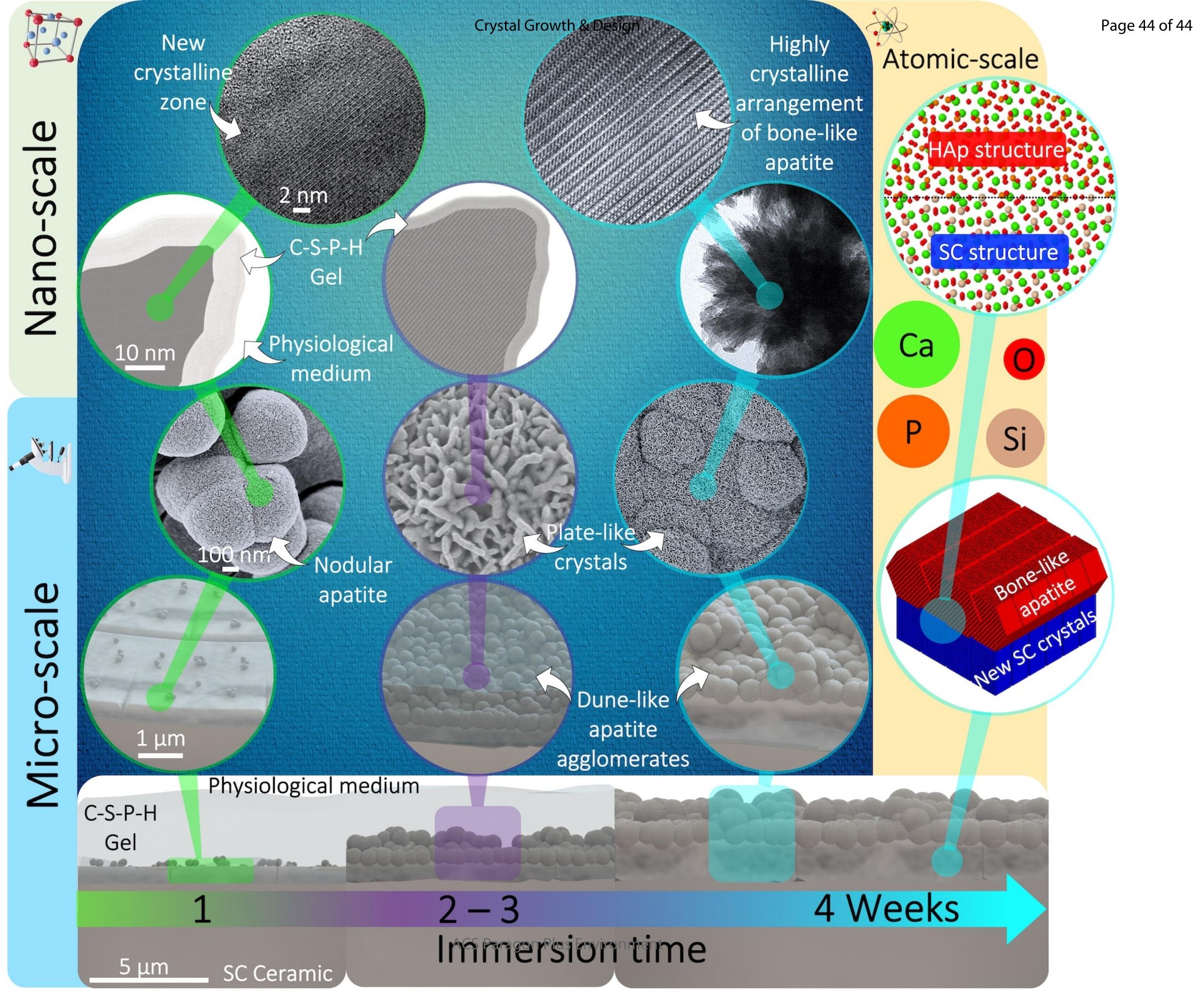

